\title{
Assessing Uncertainties of Water Footprints Using an Ensemble of Crop Growth Models on Winter Wheat
}

\author{
Kurt Christian Kersebaum ${ }^{1, *}$, Joop Kroes ${ }^{2}$, Anne Gobin ${ }^{3}$, Jozef Takáč ${ }^{4}$, Petr Hlavinka ${ }^{5,6}$, \\ Miroslav Trnka ${ }^{5,6}{ }^{\text {, Domenico Ventrella }}{ }^{7}$, Luisa Giglio ${ }^{7}$, Roberto Ferrise ${ }^{8}$, Marco Moriondo ${ }^{9}$, \\ Anna Dalla Marta ${ }^{8}$, Qunying Luo ${ }^{10}$, Josef Eitzinger ${ }^{11}$, Wilfried Mirschel ${ }^{1}$, \\ Hans-Joachim Weigel ${ }^{12}$, Remy Manderscheid ${ }^{12}$, Munir Hoffmann ${ }^{13}$, Pavol Nejedlik ${ }^{14}$, \\ Muhammad Anjum Iqbal ${ }^{1}$ and Johannes Hösch ${ }^{15}$
}

1 Leibniz Centre for Agricultural Landscape Research (ZALF), D-15374 Müncheberg, Germany; wmirschel@zalf.de (W.M.); muhammad.iqbal@zalf.de (M.A.I.)

2 Wageningen University \& Research-Environmental Research (Alterra), NL-6700 AA Wageningen, The Netherlands; joop.kroes@wur.nl

3 Flemish Institute for Technological Research (Vito NV), B-2400 Mol, Belgium; anne.gobin@vito.be

4 National Agricultural and Food Centre, Soil Science and Conservation Research Institute, SK-827 13 Bratislava, Slovakia; j.takac@vupop.sk

5 Institute of Agriculture Systems and Bioclimatology, Mendel University, CZ-613 00 Brno, Czech Republic; phlavinka@centrum.cz (P.H.); mirek_trnka@yahoo.com (M.T.)

6 Global Change Research Institute, The Czech Academy of Sciences, CZ-603 00 Brno, Czech Republic

7 Consiglio per la Ricerca in Agricoltura e L'analisi Dell'economia Agraria, Unità di Ricerca per i Sistemi Colturali degli Ambienti Caldo-Aridi, I-70125 Bari, Italy; domenico.ventrella@crea.gov.it (D.V.); luisa.giglio@crea.gov.it (L.G.)

8 Department of Agri-Food Production and Environmental Sciences, DISPAA, University of Florence, I-50144 Firenze, Italy; roberto.ferrise@unifi.it (R.F.); anna.dallamarta@unifi.it (A.D.M.)

9 Institute of Biometeorology of the National Research Council (CNR-IBIMET), I-50145 Firenze, Italy; marco.moriondo@cnr.it

10 Climate Change Cluster, University of Technology, Sydney 2007, Australia; qunying.luo@sydney.edu.au

11 Institute of Meteorology, University of Natural Resources and Life Sciences, A-1180 Vienna, Austria; josef.eitzinger@boku.ac.at

12 Thünen Institute of Biodiversity, D-38116 Braunschweig, Germany; hans.weigel@thuenen.de (H.-J.W.); remy.manderscheid@thuenen.de (R.M.)

13 Tropical Plant Production and Agricultural Systems Modelling, Georg-August-University, D-37077 Göttingen, Germany; mhoffma@gwdg.de

14 Earth Science Institute of Slovak Academy of Science, SK-840 05 Bratislava, Slovakia; nejedlik@yahoo.com 15 AGES-Austrian Agency for Health and Food Safety Ltd., A-1220 Vienna, Austria; johannes.hoesch@ages.at

* Correspondence: ckersebaum@zalf.de; Tel.: +49-33432-82-394

Academic Editor: Arjen Y. Hoekstra

Received: 18 September 2016; Accepted: 28 November 2016; Published: 5 December 2016

\begin{abstract}
Crop productivity and water consumption form the basis to calculate the water footprint (WF) of a specific crop. Under current climate conditions, calculated evapotranspiration is related to observed crop yields to calculate WF. The assessment of WF under future climate conditions requires the simulation of crop yields adding further uncertainty. To assess the uncertainty of model based assessments of WF, an ensemble of crop models was applied to data from five field experiments across Europe. Only limited data were provided for a rough calibration, which corresponds to a typical situation for regional assessments, where data availability is limited. Up to eight models were applied for wheat. The coefficient of variation for the simulated actual evapotranspiration between models was in the range of $13 \%-19 \%$, which was higher than the inter-annual variability. Simulated yields showed a higher variability between models in the range of $17 \%-39 \%$. Models responded differently to elevated $\mathrm{CO}_{2}$ in a FACE (Free-Air Carbon Dioxide Enrichment) experiment, especially regarding the reduction of water consumption. The variability of calculated WF between models was in the
\end{abstract}


range of $15 \%-49 \%$. Yield predictions contributed more to this variance than the estimation of water consumption. Transpiration accounts on average for $51 \%-68 \%$ of the total actual evapotranspiration.

Keywords: water footprint; uncertainty; model ensemble; wheat; crop yield

\section{Introduction}

The concept "Water Footprint" (WF) was introduced by [1], and later elaborated on by [2] as an indicator that relates human consumption to global water resources. Since international trade in commodities creates flows of so-called "virtual water" [2-4], by importing and exporting goods that require water for their production, the indicator provides valuable information for a global assessment of how water resources are used, although it was controversially discussed since water scarcity of the region is not accounted explicitly [5]. In recent years, WFs and virtual water was assessed for crops, goods, services, as well as on generic regional or national levels [2,4,6-9].

The Water Footprint (WF) of a crop is defined as the volume of water consumed for its production, where green and blue WF stand for rainfed and irrigation water usage, respectively [9]. A third component, the grey water footprint, is defined as the volume of freshwater that is required to dilute the load of pollutants to achieve existing ambient water quality standards. More information about the parameters involved can be found in [10].

Crop productivity and water consumption together form the basis to estimate the water footprint of a specific crop. The WF calculation is based on the estimation of crop specific evapotranspiration during the growing season, which is related to observed crop yields usually from yield statistics of a region. Analyses of several ET formulas under various climate conditions [11,12], revealed that the FAO (Food and Agriculture Organization of the United Nations) Penman-Monteith equation [13] or the Priestley-Taylor formula had the best performance across the different climatic conditions [12,14]. FAO Penman-Monteith is recommended as the standard method for estimating reference and crop evapotranspiration in the water footprint manual to estimate the water footprint [15].

Agricultural production systems are very vulnerable to a potential decrease in water availability. The impacts of climate change (increasing temperatures, shifts of seasonal precipitation and decreasing summer rainfall) could cause water limitations in many areas of Europe [16,17]. A change of currently estimated water footprint values is expected under climate change. However, it is not clear how far the above-mentioned negative impacts of a changing climate can be compensated by the positive effects of increasing $\mathrm{CO}_{2}$. Climate change including increasing $\mathrm{CO}_{2}$ concentration of the atmosphere will affect crop growth as well as soil water dynamics. Moreover, crop response to climatic drivers strongly depends on the site conditions of their habitat [18-20]. Therefore, the assessment of WF under future climate conditions requires the simulation of crop yields as well, which may add further uncertainty in the estimate.

Uncertainty may originate from three sources [21]: (i) input data; (ii) parameterization; and (iii) model structure. While uncertainty analyses of models addressing the first point are usually using combinations of stochastically distributed inputs by using, e.g., Monte-Carlo simulations (e.g., [22]), for the other two aspects recent studies have shown that the application of ensembles of complex simulation models is a valuable tool to assess the uncertainty in the estimation of climate impact on crop growth [23-27] and water consumption [28]. To assess the uncertainty of model based assessments of WF an ensemble of different crop models was applied to field data sets from five locations from across Europe. The focus of the study was mainly to look at uncertainty originating from the use of different models. Only limited basic data were made available to allow only a rough calibration, which corresponds to a typical situation for regional assessments, where data availability is limited. Although a separation between the uncertainty resulting from model structures and parameter uncertainty is not possible with this approach, the basic data provided in this study for each 
experimental site contained defined values for field capacity and wilting point and key phenological observations to keep the uncertainty caused by soil and crop parameterization at a limited level. Up to eight models were applied depending on the data set. In the comparison, we focused on cereal crops, mainly winter wheat. The objective of the study was to: (1) assess the uncertainty of the WF estimation caused by the choice of crop models; (2) analyze the response of models to management (irrigation, nitrogen fertilization) and site conditions (soils, $\mathrm{CO}_{2}$ concentration of the atmosphere); and (3) separate soil evaporation from crop transpiration to assess the difference of using evapotranspiration instead of crop transpiration for the crop water consumption assessment.

\section{Materials and Methods}

\subsection{Experimental Data}

The five datasets cover the European environmental zones of the Atlantic North, Atlantic Central, Continental and Pannonia according to [29] (Figure 1). The criteria to select data sets were that they provide: (a) meteorological and management data for several years; (b) different treatments or site conditions to analyze crop sensitivity on different inputs; and (c) data to evaluate the relevant outputs for the estimation of the water footprint, particularly crop yield and soil water (and if possible soil mineral nitrogen) status measurements. The basic characteristics of the experimental sites and the treatments used for the model inter-comparison are listed in Table 1.

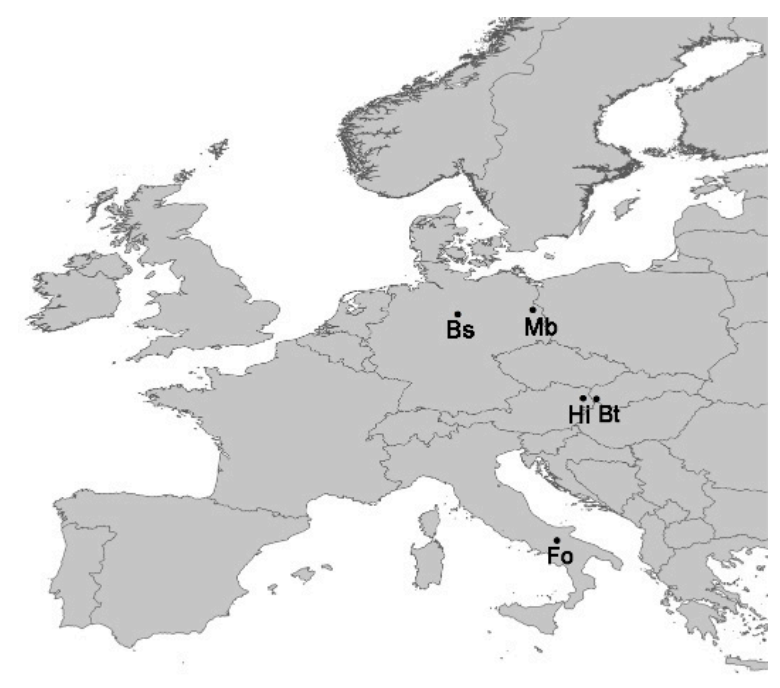

Figure 1. Location of the experimental sites.

Here some brief information for each site is presented:

The field experiment at Müncheberg (Mb), Germany was designed to study inter-annual variation in crop rotations, irrigation effects, and biomass development [30]. The crop rotation from 1992 to 1998, consisted sugar beet (Beta vulgaris L.), winter wheat (Triticum aestivum L.), winter barley (Hordeum vulgare L.), winter rye (Secale cereale L.) and oilseed radish (catch crop). The rotation covered four parallel plots with a shift of one year to establish each crop each year. Treatments included rainfed agriculture versus irrigated regime. The complete dataset is published and accessible [31].

The Braunschweig (Bs) Free-Air Carbon Dioxide Enrichment (FACE) experiment was set up to investigate interacting effects of $\mathrm{CO}_{2}$ concentration and $\mathrm{N}$ fertilization on crop production [32]. The crop rotation was composed of winter barley, a mixture of three different ryegrass cultivars (Lolium multiflorum Lam.) as a cover crop, sugar beet, and winter wheat, grown in two consecutive cycles between autumn 1999 and summer 2005. Treatments included an ambient (374 ppm) and an enriched (550 ppm) concentration of atmospheric $\mathrm{CO}_{2}$, both with a standard and a reduced $(-50 \%)$ supply of nitrogen $(\mathrm{N})$ fertilizer. Although this experiment did not include climate change, it provided 
valuable data on the response of crop growth and response of transpiration to elevated $\mathrm{CO}_{2}$, as a main driver of global warming, since both responses are still a source of uncertainty in crop as well as hydrological models.

The data from Hirschstetten (Hi), Austria were taken from three lysimeters in the agricultural region Marchfeld [33]. The crop rotation from 1998 to 2003 included mustard (Sinapis alba, catch crop), spring wheat, mustard, spring barley, winter wheat, mustard (catch crop), potato (Solanum tuberosum L.), winter wheat (ploughed due to frost damage), maize (Zea mays L.), and winter wheat. The crops were grown on three soil types (Calcic Chernozem (S1), shallow and sandy Calcaric Phaeozem (S2) and Gleyic Phaeozem (S3)) in order to study the water cycle, and the influence of soil type and rotation.

The field experiment in Foggia (Fo), Italy [34] represented a durum wheat (Triticum durum) monoculture over ten years (1996-2005) on an alluvial clay-loam soil. Treatments were different nitrogen fertilization levels following straw incorporation in autumn (T2: straw without mineral $\mathrm{N}$ application; T3: straw $+50 \mathrm{~kg} \cdot \mathrm{ha}^{-1}$; T4: $+100 \mathrm{~kg} \cdot \mathrm{N} \cdot \mathrm{ha}^{-1}$; T5: straw $+150 \mathrm{~kg} \cdot \mathrm{N} \cdot \mathrm{ha}{ }^{-1}$ ).

The field experiment in Bratislava (Bt), Slovakia consisted of a crop rotation with winter wheat, maize, and spring barley. We grouped the treatments into rainfed with (RFF) and without nitrogen fertilization (RF0) and irrigated with (IRF) and without (IR0) N. All variants were performed with and without irrigation.

Table 1. Characterization of experimental data.

\begin{tabular}{|c|c|c|c|c|c|c|}
\hline Location/Country & Topography & Period & Climate * & $\begin{array}{c}\text { Soil \# } \\
\text { S/Si/Cl/Corg }\end{array}$ & Treatment & Crops \\
\hline Müncheberg/Germany & $\begin{array}{l}\text { Lat: } 52.52^{\circ} \\
\text { Long: } 14.12^{\circ} \\
\text { Elev: } 62 \mathrm{~m} \text { a.s.l. }\end{array}$ & 1992-1998 & $\begin{array}{c}8.4^{\circ} \mathrm{C} \\
563 \mathrm{~mm}\end{array}$ & $83 / 9 / 8 / 0.6$ & $\begin{array}{l}\text { shifted rotation, } \\
\text { rainfed, irrigated }\end{array}$ & $\begin{array}{l}\text { sugar beet, winter } \\
\text { wheat, winter barley, } \\
\text { winter rye (oil raddish) }\end{array}$ \\
\hline Braunschweig/Germany & $\begin{array}{l}\text { Lat: } 52.3^{\circ} \\
\text { Long: } 10.45^{\circ} \\
\text { Elev: } 79 \mathrm{~m} \text { a.s.l. }\end{array}$ & 1999-2005 & $\begin{array}{l}10.0^{\circ} \mathrm{C} \\
642 \mathrm{~mm}\end{array}$ & $69 / 24 / 7 / 1.0$ & $\begin{array}{l}374 / 550 \text { ppm } \mathrm{CO}_{2} \\
2 \text { nitrogen levels }\end{array}$ & $\begin{array}{l}\text { winter barley, ryegrass } \\
\text { (catchcrop), sugar beet, } \\
\text { winter wheat }\end{array}$ \\
\hline Foggia/Italy & $\begin{array}{l}\text { Lat: } 41.26^{\circ} \\
\text { Long: } 15.30^{\circ} \\
\text { Elev: } 90 \mathrm{~m} \text { a.s.l. }\end{array}$ & 1995-2005 & $\begin{array}{l}15.9^{\circ} \mathrm{C} \\
540 \mathrm{~mm}\end{array}$ & $13 / 39 / 48 / 1.5$ & $\begin{array}{l}\text { Straw burned Straw } \\
\text { remained with } 0,50, \\
100 \text { and } 150 \mathrm{~kg} \mathrm{~N} / \mathrm{ha}\end{array}$ & Durum wheat \\
\hline
\end{tabular}

Notes: * Annual mean temperature and annual precipitation for the given period. \# Sand (S), silt (Si), clay $(\mathrm{Cl})$ and organic carbon (Corg) content (mass\%) in the plough layer

\subsection{Model Runs and Model Ensemble}

The simulation task for all modelers was designed to reproduce the field experimental treatments. Therefore, modelers were requested to simulate each treatment at each site, using observed information on daily weather (precipitation, minimum and maximum temperature, mean relative humidity, global radiation and mean wind speed), information on daily field management (previous crops, tillage, sowing, irrigation, fertilization and harvest) and soil properties (bulk density, texture, organic matter and water capacity parameters) as driving variables to the models.

We followed the idea of a "blind test" in order to mimic modeling practice in the event of scarce data, which is often practiced in regional climate impact studies [23-26]. Therefore, modelers were provided with a limited data set for each site depending on the availability of observation data to perform a minimal calibration of the region specific crop cultivars. The calibration data consisted of key phenological observations (dates of emergence, anthesis and maturity) for one soil of the dataset in Hirschstetten, one treatment in Bratislava and all treatments in Foggia, final biomass observations of one plot for Müncheberg, and phenological observations for the first four years at Braunschweig. 
Depending on the data set four to eight modeling teams participated in the model inter-comparison. Not all models provided results for all data sets mainly because not all crops in the crop rotation could be simulated. Since the DSSAT model was applied by two groups, seven different models were applied. Differences in DSSAT versions were minor regarding wheat simulation, but differ in their way of crop parameter calibration options (see Table 2). The models consider various processes in a different way and with different complexity. Table 2 gives a summary of the main characteristics of the models and the sites, where they were applied. Modelers were asked to provide standardized model outputs on an annual and a daily basis. Within this study we analyzed the annual outputs only.

To calculate the water footprint the model outputs for crop dry matter (d.m.) yield, and the accumulated evapotranspiration and transpiration from sowing to harvest were used. Dry matter yields were transformed to yield with standard moisture to be in line with the calculation from yield statistics. The total water footprint was calculated in $\mathrm{m}^{3}$ per ton produced yield.

To assess the error that originates from the yield component of the models, a "reference water footprint" (WF_obs*) is calculated using the simulated evaporation and the measured crop yield.

Table 2. Main characteristics of participating models.

\begin{tabular}{|c|c|c|c|c|c|c|c|}
\hline \multirow{2}{*}{ Model } & \multirow{2}{*}{$\begin{array}{l}\text { AQUA } \\
\text { CROP }\end{array}$} & \multirow{2}{*}{ APSIM } & \multirow{2}{*}{ DAISY } & DSSAT & \multirow{2}{*}{ HERMES } & \multirow{2}{*}{ SWAP/WOFOST } & \multirow{2}{*}{ CROPSYST } \\
\hline & & & & 4.5 & & & \\
\hline Abbreviation & AQ & AP & DA & DT & HE & SW & CR \\
\hline Light utilisation $^{\mathrm{a}}$ & TE & RUE & P-R & RUE & P-R & P-R & TE/RUE \\
\hline Yield formation ${ }^{b}$ & $\mathrm{Y}(\mathrm{HI}, \mathrm{B})$ & $\mathrm{Y}(\mathrm{HI}, \mathrm{B})$ & $Y($ Prt $)$ & $\mathrm{Y}(\mathrm{HI}(\mathrm{Gn}), \mathrm{B})$ & $\mathrm{Y}($ Prt $)$ & $\mathrm{Y}($ Prt,B) & Y(HI_mw/B) \\
\hline Crop phenology ${ }^{c}$ & $\mathrm{f}(\mathrm{T}, \mathrm{DL}, \mathrm{V})$ & $\mathrm{f}(\mathrm{T}, \mathrm{DL}, \mathrm{V})$ & $\mathrm{f}(\mathrm{T}, \mathrm{DL}, \mathrm{V})$ & $\mathrm{f}(\mathrm{T}, \mathrm{DL}, \mathrm{V})$ & $\begin{array}{l}\mathrm{f}(\mathrm{T}, \mathrm{DL}, \\
\mathrm{V})\end{array}$ & $\mathrm{f}(\mathrm{T}, \mathrm{DL})$ & $\mathrm{f}(\mathrm{T}, \mathrm{DL}, \mathrm{V})$ \\
\hline $\begin{array}{l}\text { Root distribution } \\
\text { over depth }^{\mathrm{d}}\end{array}$ & EXP & LIN & EXP & EXP & EXP & LIN & EXP \\
\hline Stresses involved ${ }^{\mathrm{e}}$ & $\mathrm{W}, \mathrm{N}^{\mathrm{k}}$ & $\mathrm{W}, \mathrm{N}$ & $\mathrm{W}, \mathrm{N}$ & $\mathrm{W}, \mathrm{N}$ & $\mathrm{W}, \mathrm{N}, \mathrm{A}$ & $\mathrm{W}, \mathrm{N}^{\mathrm{i}}$ & $\mathrm{W}, \mathrm{N}$ \\
\hline Water dynamics ${ }^{\mathrm{f}}$ & $\mathrm{C}$ & $\mathrm{C}$ & $\mathrm{R}$ & $\mathrm{C}$ & $\mathrm{C}$ & $\mathrm{R}$ & $\mathrm{C} / \mathrm{R}$ \\
\hline Evapotranspiration $g$ & PM & PT & PM & PT & PM & PM & PT \\
\hline Soil CN-model ${ }^{\mathrm{h}}$ & - & $\mathrm{CN}, \mathrm{P}(3), \mathrm{B}$ & $\mathrm{CN}, \mathrm{P}(6), \mathrm{B}$ & $\mathrm{CN}, \mathrm{P}(4), \mathrm{B}$ & $\mathrm{N}, \mathrm{P}(2)$ & - & $\mathrm{N}, \mathrm{P}(4)$ \\
\hline Application at & $\begin{array}{c}\mathrm{Mb}, \mathrm{Bs}, \mathrm{Hi}, \\
\mathrm{Fo}, \mathrm{Br}\end{array}$ & $\begin{array}{l}\mathrm{Mb}, \mathrm{Bs} \\
\mathrm{Hi}, \mathrm{Fo}\end{array}$ & $\begin{array}{c}\mathrm{Mb}, \mathrm{Bs}, \mathrm{Hi}, \\
\mathrm{Fo}, \mathrm{Br}\end{array}$ & $\begin{array}{l}\mathrm{Mb}, \mathrm{Bs}, \mathrm{Hi}, \\
\mathrm{Fo}, \mathrm{Br}\end{array}$ & $\begin{array}{c}\text { Mb, Bs, } \\
\text { Hi, Fo, Br }\end{array}$ & $\mathrm{Mb}, \mathrm{Bs}, \mathrm{Hi}$ & $\begin{array}{c}\mathrm{Mb}, \mathrm{Bs}, \mathrm{Hi} \\
\mathrm{Fo}, \mathrm{Br}\end{array}$ \\
\hline \multirow{2}{*}{ Calibration * } & \multirow{2}{*}{$\begin{array}{c}\mathrm{T}+\mathrm{R} \\
\mathrm{Ph}\end{array}$} & \multirow{2}{*}{$\begin{array}{c}\mathrm{T}+\mathrm{R} \\
\mathrm{Ph}\end{array}$} & \multirow{2}{*}{$\begin{array}{c}\mathrm{T}+\mathrm{R} \\
\mathrm{Ph}\end{array}$} & Aut $^{2+}$ & \multirow{2}{*}{$\begin{array}{c}\mathrm{T}+\mathrm{R} \\
\mathrm{Ph}\end{array}$} & \multirow{2}{*}{$\begin{array}{c}\mathrm{DF}+\mathrm{Aut}^{3} \\
\mathrm{Ph}\end{array}$} & \multirow{2}{*}{$\begin{array}{l}\mathrm{T}+\mathrm{R} \\
\mathrm{Ph}\end{array}$} \\
\hline & & & & $\mathrm{Ph}$ & & & \\
\hline Reference & [35] & [36] & [37] & [38] & [20] & [39] & [40] \\
\hline \multicolumn{8}{|c|}{ 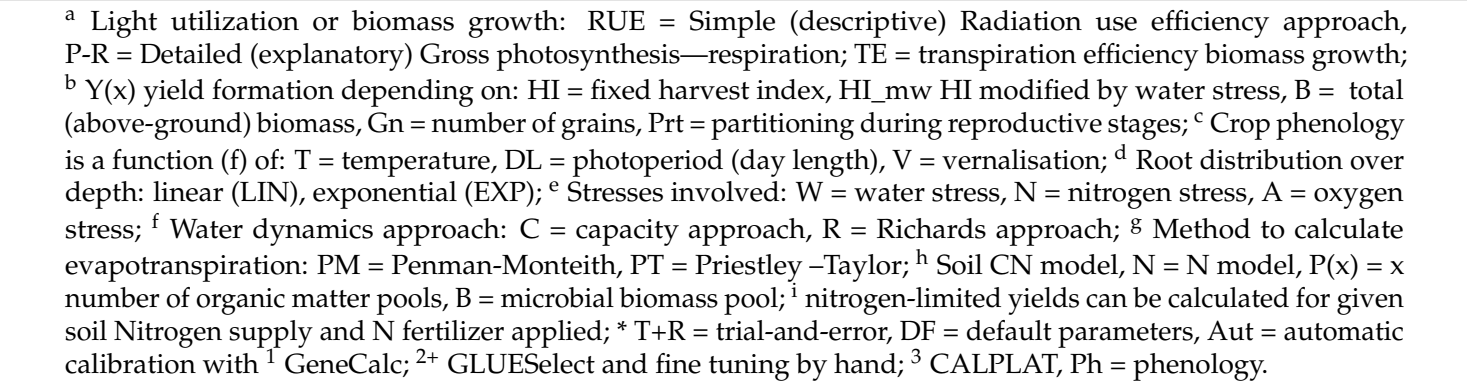 } \\
\hline
\end{tabular}

\section{Results}

\subsection{Simulated Water Consumption}

The total actual evapotranspiration (ET) was simulated from sowing to harvest of the crop. Additionally, the models provided an output of the actual crop transpiration (Tr) only. Figure 2 shows both variables for the rainfed and the irrigated variants of the Müncheberg experimental site. Due to the shifted rotation, every column represents seven seasons of winter wheat. The error bars represent the inter-annual variability of the simulations of each model. The inter-annual variability of 
the simulated ET is relatively small with $6.3 \%$ and $5.8 \%$ on average across all models for the rainfed and irrigated variants, respectively. The absolute variation is similar for the transpiration resulting in higher coefficients of variation ( $\mathrm{CV} \%$ ) due to lower absolute values of $14.7 \%$ and $12.8 \%$ for rainfed and irrigated variants, respectively. The error bars of the model ensemble mean (E-mean) represent the variation between models calculated on base of their multi-year averages. It revealed that the inter-model variability was higher than the inter-annual variability with $14.3 \%$ and $15.1 \%$ for ET and $26.8 \%$ and $26.6 \%$ for Tr of rainfed and irrigated variants, respectively. Transpiration contributes to $58 \%$ and $61 \%$ on average to the total evapotranspiration for rainfed and irrigated treatments, with the highest percentage for AQUACROP (71\% and 77\%) and the lowest for APSIM (45\% and 49\%), respectively. ET Model response to irrigation was similar showing an increase in ET and Tr, except DSSAT, which showed only a minor response.

Figure 3 shows the results of ET and Tr simulations for the FACE experiment at Braunschweig. We grouped the variants for the ambient ( $374 \mathrm{ppm}$ ) and the elevated (550 ppm) $\mathrm{CO}_{2}$ concentration. The meaning of the error bars is similar to Figure 1. Although the variability included the variance due to the two nitrogen levels, the variability between the seasons was lower than $7 \%$ for ET and lower than $13 \%$ von Tr, except for APSIM which showed a higher variance for $\operatorname{Tr}(24 \%)$. Simulated $\operatorname{Tr}$ contributed on average to $59 \%$ to ET for both $\mathrm{CO}_{2}$ concentrations ranging from $79 \%$ (374 ppm) to $76 \%$ (550 ppm) for HERMES and AQUACROP to $30 \%$ (374 ppm) to $28 \%$ for APSIM. The simulated response to elevated $\mathrm{CO}_{2}$ was different between the models. While AQUACROP, HERMES and APSIM showed a decrease in transpiration for the elevated $\mathrm{CO}_{2}$ concentration of 35,40 and $18 \mathrm{~mm}$, respectively, the two DSSAT simulations and DAISY showed nearly no response and CROPSYST and SWAP/WOFOST showed an increase by 15 and $19 \mathrm{~mm}$, respectively. Inter-model variability was again higher than the inter-annual variability and CV\% was $18 \%$ for ET and $29 \%$ and $25 \%$ for Tr at 374 and 550 ppm $\mathrm{CO}_{2}$, respectively.

Results of the ET and Tr simulations of seven models for the lysimeters at Hirschstetten, Austria are listed in Table 3. Inter-annual variability for ET and Tr is in the order of magnitude of $17 \%$ on average with only minor differences between soils. However, only two years of winter wheat were available for each soil. Lowest ET and Tr values were simulated by most of the models for the sandy Phaeozem (S2) having the lowest capacity for plant available water. Only SWAP/WOFOST and DSSAT showed minor differences between soils. Inter-model variability varied between soils with CV\% between 13\% (S2) and 19\% (S1) for ET and 20\% (S2) and 29\% (S3) for Tr. Contribution of Tr on ET was simulated highest by HERMES and AQUACROP (77\%-87\%), while lowest for DAISY and CROPSYST $(52 \%-58 \%)$ with an average across all models and soils of $68 \%$.

Table 4 summarizes the results for the Italian site at Foggia cultivated with durum wheat. Differences of ET and Tr between the treatments were small for most of the models. Only AQUACROP, DSSAT and APSIM simulated different ET and TR amounts between treatments with a maximum difference in ET of $41 \mathrm{~mm}$ simulated by AQUACROP. Inter-annual variability of ET for the 10 years of each treatment were 6\% (AQUACROP) to 16\% (HERMES) and between 10\% (AQUACROP) and $34 \%$ (CROPSYST) for Tr. However, the inter-model variability for the Italian site is slightly higher with a CV\% of $13 \%$ (T5) to $15 \%$ (T2) for ET and $29 \%(\mathrm{~T} 3, \mathrm{~T} 4, \mathrm{~T} 5)$ to $31 \%$ (T2) for Tr. Contribution of Tr to ET on average over all models and years was 53\% and ranged from $28 \%$ (CROPSYST) to $67 \%$ (AQUACROP), indicating a higher portion of soil evaporation for this experimental site. Some models (APSIM, HERMES, and DSSAT) showed a stronger response of Tr to the increasing fertilization than for ET, which increased the percentage of Tr on ET, e.g., for DSSAT from $52 \%$ to $69 \%$ due to an earlier closure of the canopy.

The results for the fifth experimental site at Bratislava, Slovakia are shown in Table 5 for the aggregated treatments. Differences of ET between the irrigated and rainfed treatments varied between models. While DAISY and DSSAT simulated nearly no effect of irrigation, HERMES, CROPSSYST and AQUACROP showed differences of 20 to $37 \mathrm{~mm}$. Interestingly, DAISY simulated even slightly lower Tr for irrigated than for rainfed treatments, which was an effect of sufficient simulated water supply under rainfed conditions on one side and of the reduction of atmospheric water demand on the 
irrigation days due to evaporation of water intercepted by leafs on the other hand, which led to slight reduction of transpiration for the irrigated treatments. The inter-annual variability of ET and $\operatorname{Tr}(\mathrm{CV} \%)$ ranged from $0.7 \%$ and $0.4 \%$ for AQUACROP and DAISY to $10 \%$ and $7.5 \%$ for DSSAT and HERMES, respectively. The inter-model variability for ET expressed as the CV\% of the model ensemble was in the range of $14 \%$ to $16 \%(27 \%-34 \%$ for $\mathrm{Tr})$ depending on the treatment showing a slight tendency to higher variability for the rainfed treatments. The percentage of Tr of the total ET was across all treatments and models at $58 \%$ with a maximum of $91 \%$ (IRF) and a minimum of $37 \%$ (RF0 and IR0) simulated by AQUACROP and DSSAT, respectively.

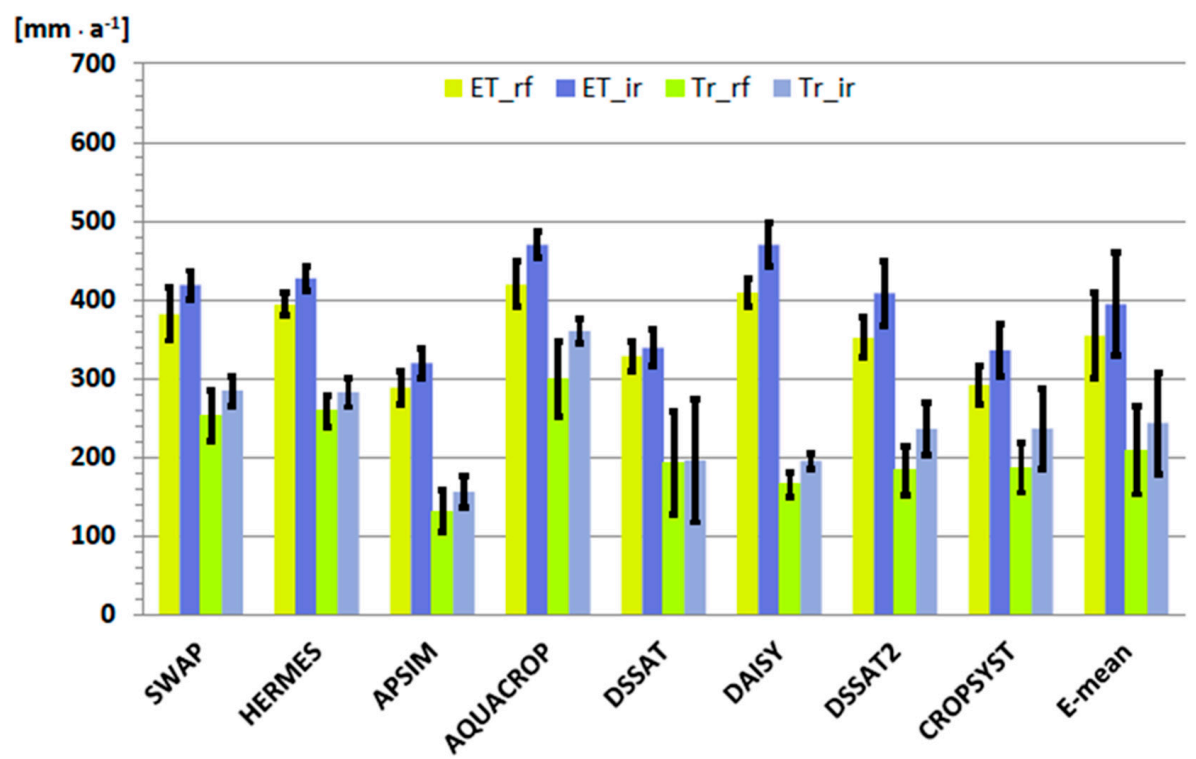

Figure 2. Simulated evapotranspiration (ET) and transpiration (Tr) for rainfed (_rf) and irrigated (_ir) variants of the Müncheberg field experiment from different models. Error bars of the model results show inter-annual variability, error bars of the ensemble mean the inter-model variability.

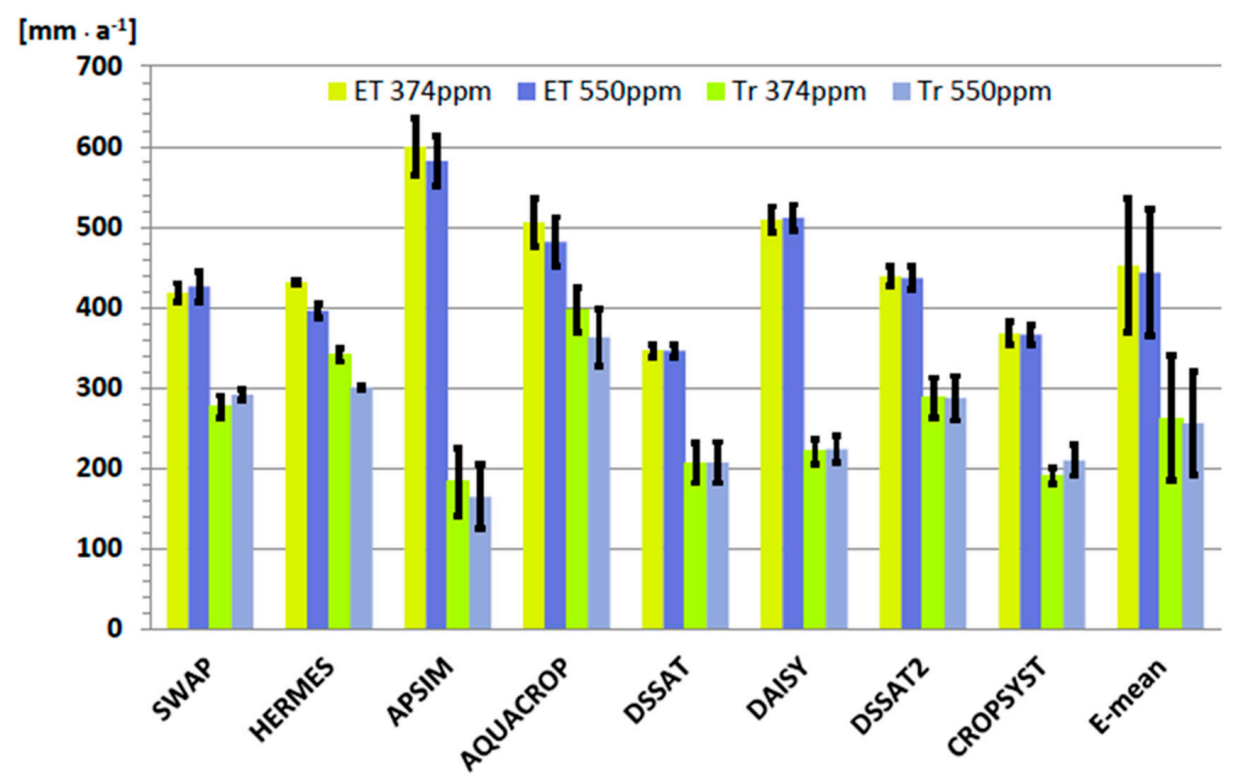

Figure 3. Simulated evapotranspiration (ET) and transpiration (Tr) for ambient (374 ppm) and elevated (550 ppm) atmospheric $\mathrm{CO}_{2}$ concentration of the Braunschweig FACE experiment from different models. Error bars of the model results show inter-annual variability, error bars of the ensemble mean the inter-model variability. 
Table 3. Simulated actual evapotranspiration (ET), transpiration (Tr), grain yield (86\% d.m.) and resulting water footprints based on ET (WF) and transpiration (WF_Tr) for winter wheat on three soils at Hirschstetten/Austria from different models. WF_obs* indicate water footprints calculated from simulated ET and measured yields. Ave is the average value, \pm indicates the range of simulated values around the mean and the standard deviation of the ensemble mean, $\mathrm{CV} \%$ is the coefficient of variation between models in percent.

\begin{tabular}{|c|c|c|c|c|c|c|c|c|c|c|c|c|c|c|c|c|c|c|}
\hline \multirow{2}{*}{ Model/Soil } & \multicolumn{3}{|c|}{ ET (mm) } & \multicolumn{2}{|c|}{$\operatorname{Tr}(\mathrm{mm})$} & \multicolumn{3}{|c|}{ Yield $\left(t \cdot h a^{-1}\right)$} & \multicolumn{2}{|c|}{ Yield obs. (t.ha $\left.{ }^{-1}\right)$} & \multicolumn{3}{|c|}{$W F\left(m^{3} \cdot t^{-1}\right)$} & \multicolumn{2}{|c|}{ WF_Tr $\left(\mathrm{m}^{3} \cdot \mathrm{t}^{-1}\right)$} & \multicolumn{3}{|c|}{ WF_obs* $\left(m^{3} \cdot t^{-1}\right)$} \\
\hline & Ave & \pm & $\mathrm{CV} \%$ & Ave & \pm & Ave & \pm & $\mathrm{CV} \%$ & Ave & \pm & Ave & \pm & $\mathrm{CV} \%$ & Ave & \pm & Ave & \pm & $\mathrm{CV} \%$ \\
\hline APSIM S1 & 469 & 11 & & 316 & 5 & 8.37 & 0.35 & & 5.19 & 0.67 & 560 & 11 & & 378 & 22 & 903 & & \\
\hline S2 & 351 & 6 & & 187 & 28 & 4.94 & 0.41 & & 2.54 & 0.34 & 713 & 48 & & 375 & 25 & 1383 & & \\
\hline S3 & 462 & 22 & & 309 & 38 & 8.49 & 0.58 & & 4.94 & 0.37 & 545 & 11 & & 363 & 20 & 936 & & \\
\hline AQUACROP S1 & 452 & 62 & & 394 & 57 & 5.15 & 0.85 & & 5.19 & 0.67 & 881 & 27 & & 768 & 17 & 871 & & \\
\hline $\mathrm{S} 2$ & 413 & 61 & & 324 & 48 & 3.64 & 0.91 & & 2.54 & 0.34 & 1164 & 123 & & 913 & 96 & 1629 & & \\
\hline S3 & 487 & 46 & & 421 & 38 & 5.20 & 0.89 & & 4.94 & 0.37 & 949 & 75 & & 821 & 69 & 986 & & \\
\hline CROPSYST S1 & 286 & 50 & & 167 & 54 & 5.04 & 1.95 & & 5.19 & 0.67 & 620 & 140 & & 341 & 24 & 551 & & \\
\hline S2 & 321 & 52 & & 186 & 43 & 5.48 & 1.70 & & 2.54 & 0.34 & 614 & 95 & & 348 & 30 & 1264 & & \\
\hline S3 & 304 & 56 & & 172 & 46 & 5.15 & 1.72 & & 4.94 & 0.37 & 624 & 100 & & 342 & 25 & 617 & & \\
\hline DAISY S1 & 494 & 54 & & 265 & 20 & 7.77 & 1.66 & & 5.19 & 0.67 & 652 & 70 & & 351 & 49 & 953 & & \\
\hline S2 & 460 & 61 & & 240 & 26 & 5.79 & 0.75 & & 2.54 & 0.34 & 821 & 211 & & 428 & 100 & 1813 & & \\
\hline S3 & 478 & 60 & & 252 & 26 & 7.97 & 1.77 & & 4.94 & 0.37 & 614 & 61 & & 325 & 40 & 969 & & \\
\hline DSSAT S1 & 346 & 39 & & 227 & 1 & 8.28 & 0.48 & & 5.19 & 0.67 & 422 & 72 & & 275 & 17 & 668 & & \\
\hline S2 & 351 & 16 & & 234 & 17 & 8.41 & 0.89 & & 2.54 & 0.34 & 424 & 64 & & 280 & 10 & 1384 & & \\
\hline S3 & 362 & 52 & & 253 & 11 & 8.77 & 1.40 & & 4.94 & 0.37 & 417 & 125 & & 290 & 34 & 733 & & \\
\hline HERMES S1 & 403 & 56 & & 341 & 31 & 4.52 & 2.31 & & 5.19 & 0.67 & 1122 & 450 & & 974 & 430 & 778 & & \\
\hline $\mathrm{S} 2$ & 362 & 60 & & 279 & 36 & 3.70 & 1.35 & & 2.54 & 0.34 & 1060 & 227 & & 829 & 206 & 1428 & & \\
\hline S3 & 401 & 38 & & 338 & 12 & 4.53 & 1.73 & & 4.94 & 0.37 & 999 & 298 & & 861 & 302 & 813 & & \\
\hline SWAP/WOFOST S1 & 350 & 37 & & 227 & 7 & 5.14 & 0.72 & & 5.19 & 0.67 & 683 & 27 & & 445 & 50 & 674 & & \\
\hline $\mathrm{S} 2$ & 352 & 40 & & 230 & 8 & 5.17 & 0.93 & & 2.54 & 0.34 & 689 & 53 & & 454 & 69 & 1389 & & \\
\hline S3 & 352 & 37 & & 231 & 5 & 5.21 & 0.79 & & 4.94 & 0.37 & 681 & 44 & & 451 & 63 & 712 & & \\
\hline Ensemble S1 & 400 & 76 & 19 & 277 & 78 & 6.33 & 1.72 & 27 & 5.19 & 0.67 & 706 & 230 & 33 & 505 & 262 & 771 & 147 & 19 \\
\hline S2 & 376 & 47 & 13 & 249 & 49 & 5.31 & 1.60 & 30 & 2.54 & 0.34 & 784 & 257 & 33 & 518 & 249 & 1470 & 187 & 13 \\
\hline S3 & 397 & 71 & 18 & 278 & 81 & 6.48 & 1.84 & 28 & 4.94 & 0.37 & 690 & 211 & 31 & 493 & 243 & 824 & 144 & 17 \\
\hline
\end{tabular}


Table 4. Simulated actual evapotranspiration (ET), transpiration (Tr), grain yield (86\% d.m.) and resulting water footprints based on ET (WF) and transpiration (WF_Tr) for winter wheat for four treatments at Foggia/Italy from different models. WF_obs* indicate water footprints based on simulated ET and measured yields. Ave is the average value, std indicates the standard deviation and CV\% the coefficient of variation in percent (only for the ensemble mean).

\begin{tabular}{|c|c|c|c|c|c|c|c|c|c|c|c|c|c|c|c|c|c|c|}
\hline \multirow{2}{*}{ Model/Treatment } & \multicolumn{3}{|c|}{ ET (mm) } & \multicolumn{2}{|c|}{$\operatorname{Tr}(\mathrm{mm})$} & \multicolumn{2}{|c|}{ Yield $\left(t \cdot h a^{-1}\right)$} & \multirow[b]{2}{*}{$\mathrm{CV} \%$} & \multicolumn{2}{|c|}{ Yield obs. $\left(t \cdot h a^{-1}\right)$} & \multicolumn{3}{|c|}{$W F\left(m^{3} \cdot t^{-1}\right)$} & \multicolumn{2}{|c|}{ WF_Tr $\left(\mathrm{m}^{3} \cdot \mathrm{t}^{-1}\right)$} & \multicolumn{3}{|c|}{ WF_obs* $\left(m^{3} \cdot t^{-1}\right)$} \\
\hline & Ave & std & $\mathrm{CV} \%$ & Ave & std & Ave & std & & Ave & std & Ave & std & $\mathrm{CV} \%$ & Ave & std & Ave & std & CV\% \\
\hline APSIM T2 & 310 & 28 & & 178 & 26 & 4.45 & 1.03 & & 3.23 & 1.30 & 718 & 109 & & 408 & 55 & 1206 & 824 & \\
\hline T3 & 323 & 31 & & 196 & 28 & 5.09 & 1.37 & & 3.08 & 1.29 & 664 & 135 & & 399 & 71 & 1418 & 1196 & \\
\hline $\mathrm{T} 4$ & 334 & 35 & & 209 & 31 & 5.65 & 1.81 & & 3.04 & 1.24 & 637 & 165 & & 393 & 85 & 1466 & 1210 & \\
\hline T5 & 338 & 34 & & 214 & 30 & 5.78 & 1.85 & & 2.96 & 1.26 & 632 & 167 & & 395 & 86 & 1615 & 1525 & \\
\hline AQUACROP T2 & 340 & 14 & & 222 & 17 & 3.32 & 0.18 & & 3.23 & 1.30 & 1025 & 62 & & 667 & 37 & 1324 & 234 & \\
\hline $\mathrm{T} 3$ & 343 & 13 & & 233 & 18 & 3.42 & 0.18 & & 3.08 & 1.29 & 1005 & 80 & & 682 & 54 & 1527 & 243 & \\
\hline $\mathrm{T} 4$ & 366 & 25 & & 247 & 25 & 3.57 & 0.29 & & 3.04 & 1.24 & 1029 & 78 & & 696 & 87 & 1532 & 231 & \\
\hline T5 & 384 & 33 & & 261 & 35 & 3.78 & 0.42 & & 2.96 & 1.26 & 1022 & 100 & & 696 & 106 & 1673 & 247 & \\
\hline CROPSYST T2 & 346 & 25 & & 96 & 33 & 2.31 & 0.73 & & 3.23 & 1.30 & 1799 & 1180 & & 413 & 37 & 1335 & 901 & \\
\hline $\mathrm{T} 3$ & 345 & 23 & & 98 & 33 & 2.35 & 0.74 & & 3.08 & 1.29 & 1766 & 1186 & & 412 & 38 & 1507 & 1295 & \\
\hline $\mathrm{T} 4$ & 345 & 23 & & 98 & 33 & 2.35 & 0.74 & & 3.04 & 1.24 & 1766 & 1186 & & 412 & 38 & 1497 & 1212 & \\
\hline T5 & 345 & 23 & & 98 & 33 & 2.35 & 0.74 & & 2.96 & 1.26 & 1766 & 1186 & & 412 & 38 & 1626 & 1507 & \\
\hline DAISY T2 & 440 & 50 & & 235 & 35 & 3.06 & 1.03 & & 3.23 & 1.30 & 1546 & 410 & & 827 & 239 & 1704 & 1223 & \\
\hline $\mathrm{T} 3$ & 440 & 50 & & 236 & 36 & 4.32 & 1.90 & & 3.08 & 1.29 & 1201 & 513 & & 647 & 293 & 1939 & 1750 & \\
\hline $\mathrm{T} 4$ & 440 & 50 & & 236 & 37 & 5.17 & 2.03 & & 3.04 & 1.24 & 973 & 377 & & 526 & 220 & 1926 & 1640 & \\
\hline T5 & 440 & 50 & & 236 & 37 & 6.07 & 2.24 & & 2.96 & 1.26 & 824 & 328 & & 444 & 183 & 2095 & 2033 & \\
\hline DSSAT T2 & 283 & 30 & & 146 & 61 & 4.10 & 2.20 & & 3.23 & 1.30 & 926 & 554 & & 383 & 67 & 1082 & 698 & \\
\hline T3 & 298 & 28 & & 179 & 43 & 5.44 & 1.66 & & 3.08 & 1.29 & 591 & 175 & & 336 & 48 & 1301 & 1114 & \\
\hline $\mathrm{T} 4$ & 302 & 30 & & 198 & 43 & 6.54 & 1.61 & & 3.04 & 1.24 & 494 & 153 & & 309 & 46 & 1313 & 1066 & \\
\hline T5 & 306 & 31 & & 211 & 42 & 7.37 & 1.53 & & 2.96 & 1.26 & 442 & 148 & & 292 & 48 & 1441 & 1337 & \\
\hline HERMES T2 & 337 & 54 & & 160 & 48 & 3.11 & 2.01 & & 3.23 & 1.30 & 1709 & 1278 & & 731 & 438 & 1293 & 932 & \\
\hline $\mathrm{T} 3$ & 335 & 54 & & 167 & 48 & 3.72 & 2.34 & & 3.08 & 1.29 & 1391 & 975 & & 649 & 411 & 1468 & 1340 & \\
\hline $\mathrm{T} 4$ & 335 & 52 & & 170 & 54 & 3.75 & 2.38 & & 3.04 & 1.24 & 1386 & 973 & & 651 & 406 & 1460 & 1258 & \\
\hline T5 & 335 & 52 & & 171 & 57 & 3.76 & 2.41 & & 2.96 & 1.26 & 1384 & 974 & & 651 & 406 & 1589 & 1561 & \\
\hline Ensemble T2 & 343 & 53 & 15 & 173 & 51 & 3.39 & 0.77 & 23 & 3.23 & 1.30 & 1287 & 454 & 35 & 571 & 194 & 1327 & 209 & 16 \\
\hline $\mathrm{T} 3$ & 347 & 49 & 14 & 185 & 51 & 4.06 & 1.14 & 28 & 3.08 & 1.29 & 1103 & 447 & 40 & 521 & 154 & 1527 & 217 & 14 \\
\hline $\mathrm{T} 4$ & 354 & 47 & 13 & 193 & 54 & 4.50 & 1.55 & 34 & 3.04 & 1.24 & 1047 & 472 & 45 & 498 & 153 & 1543 & 209 & 14 \\
\hline T5 & 358 & 47 & 13 & 199 & 58 & 4.85 & 1.86 & 38 & 2.96 & 1.26 & 1012 & 492 & 49 & 482 & 158 & 1694 & 227 & 13 \\
\hline
\end{tabular}


Table 5. Simulated actual evapotranspiration (ET), transpiration (Tr), grain yield (86\% d.m.) and resulting water footprints based on ET (WF) and transpiration (WF_Tr) for winter wheat for rainfed and irrigated combined with fertilized and unfertilized treatments at Bratislava/Slovakia from different models. WF_obs* indicate water footprints based on simulated ET and measured yields. Ave is the average value, std indicates the standard deviation and CV\% the coefficient of variation in percent (only for the ensemble mean).

\begin{tabular}{|c|c|c|c|c|c|c|c|c|c|c|c|c|c|c|c|c|c|c|}
\hline \multirow{2}{*}{ Model/Treatment } & \multicolumn{3}{|c|}{ ET (mm) } & \multicolumn{2}{|c|}{$\operatorname{Tr}(\mathrm{mm})$} & \multicolumn{3}{|c|}{ Yield $\left(t \cdot h a^{-1}\right)$} & \multicolumn{2}{|c|}{ Yield obs. $\left(t \cdot h a^{-1}\right)$} & \multicolumn{3}{|c|}{$\mathrm{WF}\left(\mathrm{m}^{3} \cdot \mathrm{t}^{-1}\right)$} & \multicolumn{2}{|c|}{ WF_Tr $\left(\mathrm{m}^{3} \cdot \mathrm{t}^{-1}\right)$} & \multicolumn{3}{|c|}{ WF_obs* $\left(\mathrm{m}^{3} \cdot \mathrm{t}^{-1}\right)$} \\
\hline & Ave & std & CV\% & Ave & std & Ave & std & $\mathrm{CV} \%$ & Ave & std & Ave & std & $\mathrm{CV} \%$ & Ave & std & Ave & std & $\mathrm{CV} \%$ \\
\hline AQUACROP RF0 & 488 & 26 & & 353 & 53 & 6.35 & 1.02 & & 5.74 & 0.10 & 780 & 102 & & 557 & 11 & 745 & 137 & \\
\hline RFF & 506 & 28 & & 455 & 47 & 7.86 & 0.76 & & 7.50 & 1.89 & 646 & 28 & & 578 & 13 & 751 & 111 & \\
\hline IR0 & 525 & 4 & & 403 & 26 & 7.23 & 0.48 & & 6.04 & 0.44 & 729 & 46 & & 558 & 12 & 847 & 185 & \\
\hline IRF & 536 & 15 & & 486 & 35 & 8.33 & 0.62 & & 7.69 & 1.98 & 645 & 30 & & 584 & 14 & 824 & 192 & \\
\hline CROPSYST RF0 & 398 & 17 & & 189 & 9 & 5.33 & 0.30 & & 5.74 & 0.10 & 747 & 18 & & 355 & 4 & 693 & 24 & \\
\hline RFF & 395 & 14 & & 190 & 10 & 5.36 & 0.34 & & 7.50 & 1.89 & 738 & 21 & & 355 & 4 & 550 & 126 & \\
\hline IR0 & 420 & 25 & & 211 & 20 & 5.90 & 0.56 & & 6.04 & 0.44 & 714 & 33 & & 358 & 5 & 695 & 20 & \\
\hline IRF & 429 & 3 & & 224 & 5 & 6.23 & 0.05 & & 7.69 & 1.98 & 688 & 1 & & 359 & 6 & 589 & 163 & \\
\hline DAISY RF0 & 596 & 7 & & 276 & 2 & 4.66 & 0.64 & & 5.74 & 0.10 & 1299 & 208 & & 601 & 90 & 1039 & 14 & \\
\hline RFF & 597 & 7 & & 278 & 1 & 8.95 & 2.28 & & 7.50 & 1.89 & 699 & 171 & & 327 & 85 & 834 & 209 & \\
\hline IR0 & 596 & 8 & & 269 & 1 & 5.10 & 0.49 & & 6.04 & 0.44 & 1179 & 135 & & 532 & 57 & 991 & 65 & \\
\hline IRF & 597 & 8 & & 271 & 1 & 9.67 & 1.47 & & 7.69 & 1.98 & 627 & 90 & & 285 & 43 & 817 & 212 & \\
\hline DSSAT RF0 & 435 & 42 & & 162 & 11 & 5.35 & 1.30 & & 5.74 & 0.10 & 870 & 167 & & 326 & 71 & 757 & 66 & \\
\hline RFF & 437 & 35 & & 173 & 1 & 5.53 & 1.01 & & 7.50 & 1.89 & 688 & 52 & & 272 & 1 & 603 & 112 & \\
\hline IR0 & 437 & 44 & & 162 & 12 & 6.35 & 0.02 & & 6.04 & 0.44 & 771 & 30 & & 288 & 19 & 723 & 41 & \\
\hline IRF & 438 & 35 & & 173 & 0 & 6.35 & 0.02 & & 7.69 & 1.98 & 689 & 53 & & 273 & 1 & 592 & 116 & \\
\hline HERMES RF0 & 460 & 37 & & 340 & 25 & 8.28 & 1.96 & & 5.74 & 0.10 & 572 & 94 & & 423 & 71 & 802 & 73 & \\
\hline RFF & 458 & 37 & & 350 & 26 & 9.91 & 2.18 & & 7.50 & 1.89 & 473 & 66 & & 362 & 53 & 651 & 219 & \\
\hline IR0 & 476 & 33 & & 357 & 20 & 8.89 & 1.27 & & 6.04 & 0.44 & 540 & 48 & & 405 & 39 & 793 & 109 & \\
\hline IRF & 478 & 30 & & 371 & 18 & 11.22 & 0.76 & & 7.69 & 1.98 & 426 & 17 & & 331 & 12 & 663 & 218 & \\
\hline Ensemble RF0 & 475 & 75 & 16 & 264 & 86 & 5.96 & 1.43 & 24 & 5.74 & 0.10 & 854 & 272 & 32 & 452 & 122 & 807 & 135 & 17 \\
\hline RFF & 479 & 77 & 16 & 289 & 117 & 7.69 & 1.85 & 24 & 7.50 & 1.89 & 649 & 104 & 16 & 379 & 117 & 678 & 114 & 17 \\
\hline IR0 & 491 & 72 & 15 & 281 & 100 & 6.56 & 1.52 & 23 & 6.04 & 0.44 & 786 & 236 & 30 & 428 & 115 & 810 & 117 & 14 \\
\hline IRF & 495 & 71 & 14 & 305 & 125 & 8.36 & 2.15 & 26 & 7.69 & 1.98 & 615 & 109 & 18 & 366 & 127 & 697 & 117 & 17 \\
\hline
\end{tabular}




\subsection{Simulated Crop Yield}

For comparability, simulated and measured dry matter grain yields for winter wheat were transformed to standard yields as used in statistics by assuming a moisture content of $14 \%$. Figure 4 shows the inter-comparison of yield estimations from eight models applied for the Müncheberg experimental site. The inter-annual variability of the yield estimations was $28 \%$ and $25 \%$ on average across all models for the rainfed and irrigated treatment, respectively. This was lower than the observed $\mathrm{CV} \%$ of $43 \%$ and $33 \%$, but confirmed that irrigation reduced the inter-annual variability. The ensemble mean slightly overestimated the observed grain yield by 0.7 and $0.35 \mathrm{t} \cdot \mathrm{ha}^{-1}$, which correspond to $12 \%$ and $5 \%$ of the observed yields. Only AQUACROP and DSSAT2 showed a similar good performance, while SWAP and HERMES overestimated and APSIM and DSSAT underestimated grain yields. The difference between the two DSAAT simulations is an indicator concerning the magnitude of user impact on model performance.

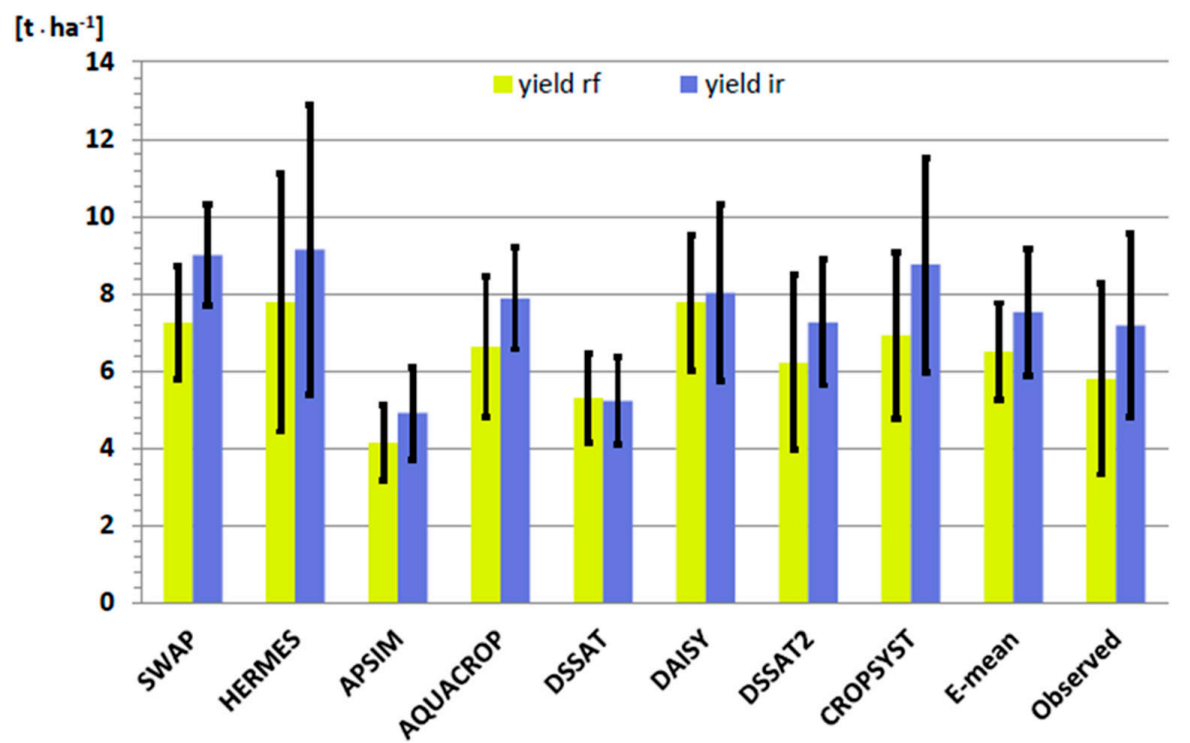

Figure 4. Simulated grain yields of winter wheat for rainfed (_rf) and irrigated (_ir) variants of the Müncheberg field trial from different models. Error bars of the model results and observations show inter-annual variability, error bars of the ensemble mean the inter-model variability.

The simulated yields of the FACE experiments at Braunschweig are shown in Figure 5. As expected, all models simulated an increase of grain yields under the elevated $\mathrm{CO}_{2}$ concentration. However, the magnitude was different ranging from 2.1\% (APSIM) to 35\% for CROPSYST. The ensemble mean showed a $\mathrm{CO}_{2}$ effect of $+13.6 \%$, which was close to the observed yield increase of $11.5 \%$ as described in [32]. AQUACROP and the ensemble mean were closest to the observed yields.

Yield simulations for the more loamy soils (S1 and S3) at Hirschstetten (Table 3) showed a close fit $\left(<0.7 \mathrm{t} \cdot \mathrm{ha}^{-1}\right)$ for four out of seven models. DSSAT, APSIM and DAISY overestimated yield for these soils significantly. All models overestimated grain yield on the more sandy soil S2, which is also reflected by the ensemble mean. The inter-model variability expressed by the coefficient of variation of the ensemble mean was at $27 \%$ to $30 \%$, which reflects a much higher model uncertainty for the yield estimation than for ET simulations.

Durum wheat yield simulations at Foggia showed even higher variations between the models (Table 4) from $25 \%$ to $39 \%$ especially for the treatments with higher fertilization. This is mainly because DAISY and DSSAT showed a strong response to the higher fertilization, while APSIM and HERMES showed no or only a slight response, which corresponds better to the observed yields showing nearly no response of crop yields as well. The simulated inter-annual variability was on average $39 \%$ ranging from $29 \%$ (APSIM) to $64 \%$ (HERMES) compared to $41 \%$ for the observed yields. 


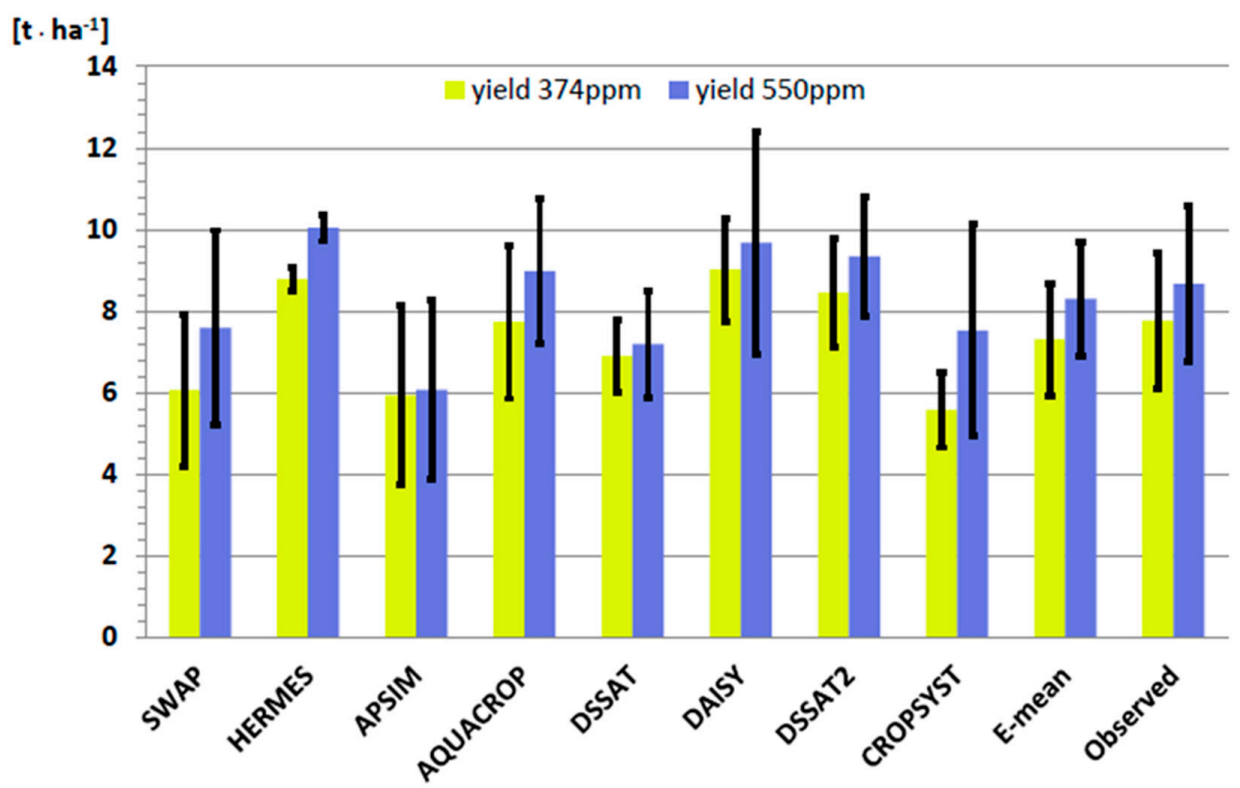

Figure 5. Simulated winter wheat grain yields for ambient (374 ppm) and elevated (550 ppm) atmospheric $\mathrm{CO}_{2}$ concentration of the Braunschweig FACE experiment from different models. Error bars of the model results and observations show inter-annual variability, error bars of the ensemble mean the inter-model variability.

Crop yields at Bratislava (Table 5) were best estimated by the ensemble mean followed by AQUACROP. DAISY underestimated the fertilized treatments while overestimated the irrigated treatments. HERMES overestimated all treatments. The inter-model variability was $23 \%-26 \%$, compared to an inter-annual CV\% of $15 \%$ on average for the simulations of the rainfed treatments and $8.5 \%$ for the irrigated plots. Fertilization reduced in both cases the inter-annual variability. Inter-annual variability of observations showed $\mathrm{CV} \%$ of $13.4 \%$ for rainfed and $16.6 \%$ for irrigated treatments. However, no fertilization reduced the observed inter-annual yield variability more than irrigation showing the lowest $\mathrm{CV} \%$ of $1.7 \%$ and $7.3 \%$ for the rainfed and irrigated plots, respectively.

\subsection{Water Footprint}

Model results in Section 3.1 showed that there is a distinct difference between ET and Tr indicating that water consumption might be overestimated using ET. Therefore, we calculated water footprints alternatively using the simulated transpiration. To quantify the uncertainty caused by the inter-model variability of yield prediction we calculated the water footprint based on the simulated ET and the observed grain yields, which is annotated in Figures 6 and 7 as "observed" and as "WF_obs" in the tables. We used an overall water footprint instead of dividing it into $\mathrm{WF}_{\text {green }}$ and $\mathrm{WF}_{\text {blue }}$ for a better comparison of ranges of the model ensemble between locations.

Figure 6 contains the water footprints calculated for the Müncheberg field trial based on ET and Tr. Water footprints of the irrigated treatment were smaller than for rainfed variants for most of the models, which means that water use efficiency was higher due to a strong positive response of wheat yields on irrigation. However, DSSAT and DAISY showed an opposite trend indicating that the increase of water consumption was higher than the positive effect on crop yields. While the behavior is similar for ET and Tr based calculations for most models, the results of DSSAT2 showed an increase of WF_ET but a decrease of WF_Tr for the irrigated treatment. The inter-annual variability was estimated to be $27 \%$ on average for rainfed and $25 \%$ for irrigated treatments, which corresponded to the high inter-annual yield variability on the sandy soil (see Section 3.2). However, the variation between models for the ET based water footprint was relatively small with CV\% of $15 \%$ and $18 \%$ of the rainfed and irrigated plots, respectively. Variation was slightly higher ( $21 \%$ for rainfed and $19 \%$ 
for irrigated) for the WF_Tr. Related to the estimated low contribution of Tr to the total ET, the water footprints based on $\operatorname{Tr}$ were on average across all models distinctly lower making $58 \%$ and $60 \%$ of the WF_ET for rainfed and irrigated treatments, respectively. Differentiation between green and blue water footprints revealed that the relative blue partition increased if Tr was used instead of ET for the calculation. The mean of the model ensemble was closer to the mean based on observed crop yields than any of the single models. DSSAT2 and AQUACROP simulations were closest on average over the two treatments.

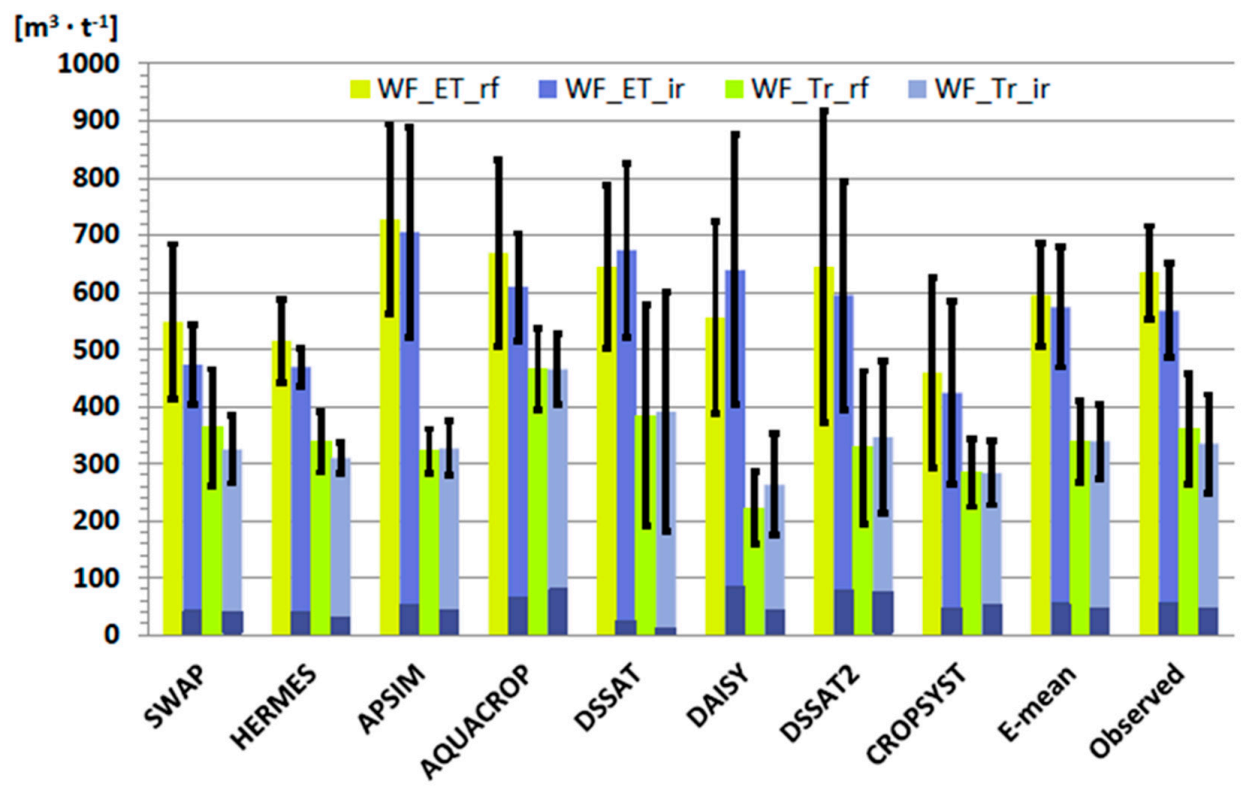

Figure 6. Water footprints of winter wheat calculated from simulations of different models for rainfed (_rf) and irrigated (_ir) variants of the Müncheberg field trial. Calculations were based on ET (WF_ET) and $\operatorname{Tr}$ (WF_Tr). Error bars of the model results and observations show inter-annual variability, error bars of the ensemble mean the inter-model variability. "Observed" is calculated from simulated ET and Tr and observed yields. Dark blue columns in WF_ET_ir and Tr_ir show the blue WF based on ET and $\mathrm{Tr}$, respectively.

The calculated water footprints for the two different $\mathrm{CO}_{2}$ concentrations of the FACE experiment at Braunschweig/Germany are shown in Figure 7. All models showed a reduction of the water footprints for the elevated $\mathrm{CO}_{2}$ concentration indicating a higher water use efficiency under higher $\mathrm{CO}_{2}$ concentration. However, the response of DAISY and DSSAT was very low. Although SWAP showed an increase of ET and $\operatorname{Tr}$ (see Figure 3 in Section 3.1) with rising $\mathrm{CO}_{2}$, this is over-compensated by the increase of yields resulting in a distinct reduction of the water footprint. Highest water footprints were calculated by APSIM, while HERMES resulted in lower values. The inter-model variability for WF_ET increases from 30\% to $34 \%$ from ambient to elevated $\mathrm{CO}_{2}$, while the $\mathrm{CV} \%$ of WF_Tr decreased from $26 \%$ to $19 \%$. Inter-annual variability of WF_ET was at $17 \%$ and $21 \%$ (15\% and $18 \%$ for WF_Tr) on average of all models for 374 and $550 \mathrm{ppm}$, respectively.

For Hirschstetten water footprints differed among soils (Table 3). However, the effect of soil on WF_Et and WF_Tr was small for CROPSYST, DSSAT and SWAP, which corresponded to their low sensitivity of crop yields on soils (see Section 3.1). Most of the other models showed higher water footprints for the sandy Phaeozem (S2), which reflect also the trend of the water footprints calculated on the base of observed crop yields. Only HERMES simulated even higher water footprints for S1, which is mainly due to a clear underestimation of yield in the first year. The inter-model variability was $31 \%$ to $33 \%$ for the WF_ET and $48 \%$ to $52 \%$ for WF_Tr. Since the models over-predicted yields on average, the WF_ETs were under-estimated compared to the values calculated with the measured yields, which is more pronounced on the sandy soil (S2), where WF_ET was only 53\% of WF_obs*. 


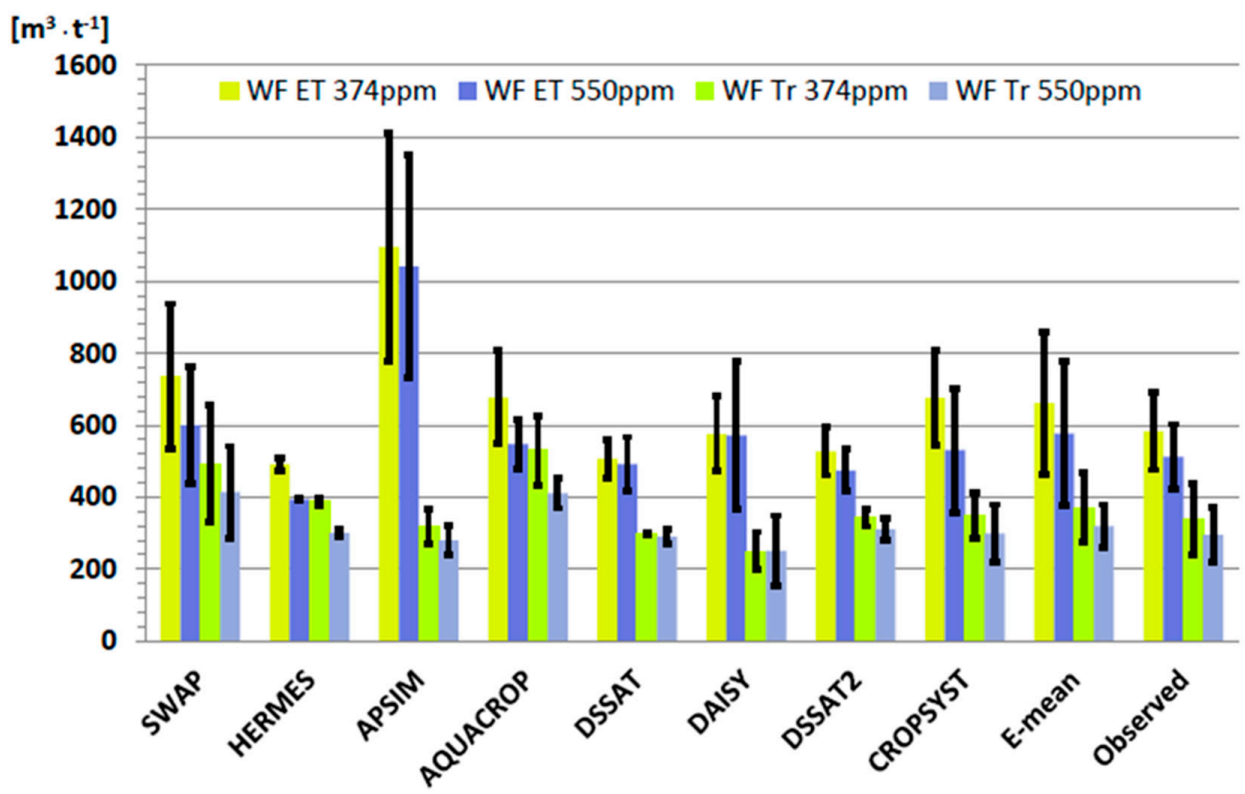

Figure 7. Water footprints of winter wheat calculated from simulations of different models for ambient (374 ppm) and elevated (550 ppm) $\mathrm{CO}_{2}$ concentrations of the FACE experiment at Braunschweig/Germany. Error bars of the model results and observations show inter-annual variability, error bars of the ensemble mean the inter-model variability. "Observed" is calculated from simulated ET and Tr and observed yields.

Water footprints calculated with observed durum wheat yields showed on average over all models a slight increase with increasing nitrogen fertilization (Table 4). However, the ensemble mean of the models for WF_ET and WF_Tr showed an opposite trend. Additionally, the inter-model variability was very high and varied from $36 \%$ for treatment $\mathrm{T} 2$ to $55 \%$ for $\mathrm{T} 5$. This is mainly due to the diversity of simulated crop yield response to the treatments since the variability of water footprints calculated with observed yields was only $15 \%$ to $18 \%$. On the other hand,WF_ET showed a very high inter-annual variability of more than $70 \%$. Due to the low percentage of Tr on ET (see Section 3.1) the difference between WF_ET and WF_Tr is especially high for the Italian site and WF_Tr was estimated on average over all treatments to be only $43 \%$ of WF_ET.

Results for Bratislava/Slovakia (Table 5) showed about 30\% higher water footprints for non-fertilized compared to fertilized treatments, while the effect of irrigation was only $-8 \%$ compared to rainfed. Inter-annual variability was reduced on average from $12 \%$ to $7 \%$ from rainfed to irrigated treatments. The inter-model variability was $18 \%$ and $18 \%$ for the fertilized treatments of rainfed and irrigated plots, compared to $32 \%$ and $30 \%$ for the unfertilized plots respectively. Using the observed crop yields for the estimation of the water footprints results the variability of the unfertilized treatments distinctly, which indicates that the uncertainty originated to a large extent from uncertainty of nutrient supply from the soils.

\section{Discussion}

The results from five sites across Europe showed that the uncertainty in the estimation of evapotranspiration (ET) expressed through the coefficient of variation of the model ensemble was in the order of magnitude of $13 \%$ to $19 \%$. Similar variation (15\%) was observed in a comparison of nine models applied to one of the rainfed plots of the Müncheberg data set [41]. Since the absolute standard deviations of ET and Tr were in the same order of magnitude, most of the uncertainty comes from the simulation of transpiration, which showed coefficients of variation from $13 \%$ to $34 \%$ due to the lower mean value. This result was in line with findings from [28], who compared sixteen crop models regarding their uncertainty of wheat water use covering four sites across the world. He 
found coefficients of variation for transpiration among models from $19.8 \%$ to $33.2 \%$ and came to the conclusion that transpiration contributed most to the uncertainty to crop water use. Uncertainty from the parameterization of soil hydraulic parameters was mainly reduced since models were provided with field capacity and wilting point values for each soil profile. The same holds for the length of the growing period since flowering and ripening dates were provided for rough calibration. Most of the modelers used the trial and error approach for calibrating the phenological development of the crops. The comparison of the results from the two DSSAT groups show, that transpiration simulations at Müncheberg were quite similar, while ET values differed more. However, at Braunschweig the differences between both groups were high for Tr and ET. Differences in the initialization of soil moisture and nitrogen of the models could be a reason for the differences in ET calculation, especially because the DSSAT simulations were re-initialized every year instead of using continuous simulation over the crop rotation and initial measured values were only provided for the first year. Although this could be accounted as input error it could also be related to the model structure which makes it difficult to run the model in a continuous mode. Finally, parameter errors are related to some extent related to model structure increasing with model complexity [42]. One example might be the discussion on the Tr response to elevated $\mathrm{CO}_{2}$ below. Beside the errors from inputs, parameters and model structure, the users of the models are another source of uncertainty [43], especially when trial and error approaches are used.

Another conclusion of the study of [28] was, that uncertainty increases with higher $\mathrm{CO}_{2}$ concentration. However, our results from the Braunschweig FACE experiment revealed, that the coefficient of variation for the simulated transpiration at elevated $\mathrm{CO}_{2}$ was slightly smaller than for the ambient concentration. Although some models did not reflect the reduction of water use caused by rising $\mathrm{CO}_{2}$ concentration as it was shown in a field chamber study with wheat by [44], the beneficial effect on crop yields was reflected by all models leading to a decrease of water footprint under elevated $\mathrm{CO}_{2}$. This was in agreement with the observed increase of water use efficiency [44]. However, the fact that reduction of water use was not reflected in some model results did not mean that the effect of increasing $\mathrm{CO}_{2}$ on stomata resistance was not considered at all in these models. In SWAP, for example, reduction of transpiration by increased stomata resistance under elevated $\mathrm{CO}_{2}$ was overcompensated by the increase in crop biomass and consequently in LAI. Other models use fixed or phenology driven $\mathrm{kc}$ factors and modify transpiration by factors (DSSAT) or by modifying stomatal resistance without considering changes in LAI (HERMES). The increase of water use efficiency or reduction in water footprints was even found under conditions of projected climate change, where potential evaporation increased due to warming $[20,45]$.

In our study we found an increase of the estimated water footprints from North to South, which was also found in regional estimations e.g., by [15] or global studies [9,46]. Additionally, results from Bratislava showed the effect of insufficient fertilization on the water footprint, a situation, which can be often found in regions of high poverty, e.g., sub-Saharan Africa, leading to very low water use efficiency or high water footprints due to nutrient limited crop growth.

Water footprints estimated from simulated crop yields showed a high uncertainty indicated by the coefficient of variation of the model ensemble ranging from $15 \%$ to $18 \%$ for Müncheberg to $23 \%$ to $55 \%$ for the durum wheat in Foggia. Replacing simulated by observed crop yields could reduce the CV\% for Hirschstetten, Foggia and Bratislava substantially leading to the conclusion that uncertainty of crop modeling contributed significantly to the uncertainty of the water footprint derived from simulated yields. Uncertainty of models was recently reported by several model inter-comparisons [23,25,27] showing very high ranges of model results for wheat yields, when models were applied only with minimum calibration. However, the inter-model variability could be significantly reduced when models are fully calibrated with suitable data for each location resulting that more than $50 \%$ of the simulated yields were below a CV\% of $13.5 \%$, which corresponds to the experimental error [25]. Uncertainty for durum wheat was higher in our study since not all models were applied for durum wheat before. In their model, inter-comparison of crop models applied for crop rotations [47] pointed 
out that model performance to predict crop yields was lower for crops that were not often simulated by the modelers before.

Our results for the fertilized and unfertilized plots of the Bratislava field experiment showed that nutrient limitation led to much higher inter-model variation of water footprints. Using measured crop yields reduced the CV\% by $53 \%$ (from $30 \%$ to $14 \%$ ). The variation in the nitrogen response of the models can add to the uncertainty of crop modeling. In their comparison of eleven models regarding their response to different nitrogen levels [48], came to the conclusion that uncertainty regarding the simulation of nitrogen release by mineralization was one of the main factors influencing the performance of crop models. Uncertainties are related to different structures of the $\mathrm{N}$ turnover modules in models [49], differences in their temperature responses [50] or in the estimation of initial mineralization parameters, which might be even a consequence of lacking long term history data on land management.

Soil information can have a strong influence on the regional assessment of climate impacts on crop yields [20] and water footprints [45]. The impact of soil was obvious for the lysimeters at Hirschstetten. Especially the overestimation of wheat yield for the sandy soil by some models led to a high inter-model variability and a distinctive underestimation of the water footprint compared to the calculation based on the observed yields. The uncertainty of rooting depth was identified as one major impact to the high variability and overestimation of another model ensemble for this soil [47].

Our results also indicated that the approach described in the water footprint manual [10] to use evapotranspiration for crop water use to calculate the water footprint of a crop might be worth to be discussed. We found that crop transpiration makes only $51 \%-68 \%$ of the total actual evapotranspiration on average across models showing a large variance between models. Similar relations were found by [28], who documented Tr to ET contributions of $56 \%$ to $77 \%$. The rationale of the indicator is to represent consumptive water use by agricultural production at all and should be sensitive to agricultural management. However, water saving practices like advanced irrigation techniques or deficit irrigation are often applied when the crop canopy is mainly closed and soil evaporation plays a negligible role. Therefore, transpiration would be in most cases more responsive than ET, which is also shown in Figure 6 for the irrigated treatments. On average the contribution of the blue partition is $5 \%$ higher for TR compared to ET based WF. At Foggia, Tr showed a stronger response to increasing nitrogen supply compared to ET (see Section 3.1, Table 4). Other practices like mulching or tillage are mainly influencing evaporation during the time when no crop is on the soil. Therefore, these effects would not be accounted sufficiently for because the water footprint calculation just uses the ET between sowing and harvest. Inclusion of unproductive soil evaporation, which might not be accounted for the water consumption of a crop since it would occur even without crop cover, should therefore be discussed. An alternative would be to look at cropping systems as a whole including the fallow periods, but this would make it difficult to attribute the water consumption to a specific crop or product. Post-seasonal ET was not provided by all models and periods between harvest and sowing of the next crop varied due to different crop rotations, which made it difficult to compare results. For the durum wheat monoculture at Foggia, results of two models showed that post-seasonal ET contributes on average to $38 \%$ to the annual ET.

Finally, it should be noted that the model results should not be used to judge the suitability of a particular model, since information provided were basic and model performance could be certainly improved if more information would be available. We therefore did not apply model performance indicators. However, from the comparison of fully model derived water footprints to footprints using only simulated ET and observed crop yields we have to state that no model performed best on all sites and treatments and that, similar to other model inter-comparisons [19-23], the ensemble means were in most cases among the estimates closest to the footprints with observed yields. 


\section{Conclusions}

The use of agro-ecosystem models is indispensable to assess impacts of climate change on crop production and resource use efficiency. However, limited opportunities to calibrate models on a regional scale and scarcity of management data at this scale imply higher uncertainties, especially regarding the prediction of crop production. Our study revealed that the uncertainty of crop yield prediction caused by the use of different models contributes more to the uncertainty in the assessment of future development of water use efficiency and water footprint calculation than the estimation of evapotranspiration. This is mainly because calculation of ET was much more standardized across the models and formulas for ET are similar. The insight that a regional calibration of crop models is recommendable to reduce uncertainty from yield predictions seems to be trivial. However, the uncertainty remains since the possibility to calibrate crop parameters for the future is limited. Recent model inter-comparisons have shown that the amount of information used for calibration has only a minor effect on most models' climate response [51] and that crop response to external drivers, e.g., $\mathrm{CO}_{2}$ concentration or heat stress, is still an issue of research and source of uncertainty $[28,51,52]$. Increasing model complexity may cause higher parameter uncertainties, which was shown in the different responses of transpiration on elevated $\mathrm{CO}_{2}$ at Braunschweig. The choice of the most suitable model seems to be difficult since recent model inter-comparisons showed that there was no ultimate best model, which outperforms the ensemble mean or median [23-27].

Regarding the definition of water use for the water footprint calculation, our results indicate that the contribution of soil evaporation is not negligible and actual crop water use by transpiration is much less than the total evapotranspiration. Our results also show some evidence that $\mathrm{Tr}$ responds more sensitive than ET on different treatments. Therefore, the appropriateness to attribute actual seasonal evapotranspiration to crop water use requires a critical review for further water footprint and virtual water trade assessments.

Acknowledgments: The study was performed under the umbrella of COST ES1106. Kurt Christian Kersebaum and Domenico Ventrella received additional support from the German Federal Office for Agriculture and Food (BLE) (2812ERA 147) and Italian Ministry for Agricultural, Food and Forestry Policies, respectively, within the framework of JPI FACCE MACSUR. Anne Gobin obtained additional support from Belspo contract No. SD/RI/03A. Petr Hlavinka and Miroslav Trnka were supported by funding from the Ministry of Education, Youth and Sports of the Czech Republic within the National Sustainability Program I (NPU I), grant number LO1415, project IGA AF MENDELU No. TP 7/2015 with the support of the Specific University Research Grant and LD13030 project supporting Czech activities of the COST ES1106 action, Muhammad Anjum Iqbal got a fellowship by Alexander von Humboldt Foundation.

Author Contributions: Hans-Joachim Weigel and Remy Manderscheid performed the FACE experiment; Hans-Joachim Weigel, Remy Manderscheid, Domenico Ventrella, Anna Dalla Marta, Wilfried Mirschel, Kurt Christian Kersebaum, Josef Eitzinger, Johannes Hösch, Jozef Takáč and Pavol Nejedlik provided and prepared experimental data; Kurt Christian Kersebaum, Joop Kroes, Anne Gobin, Jozef Takáč, Petr Hlavinka, Miroslav Trnka, Domenico Ventrella, Luisa Giglio, Roberto Ferrise, Marco Moriondo, Qunying Luo and Munir Hoffmann did the simulations; Kurt Christian Kersebaum and Muhammad Anjum Iqbal analyzed the data and Kurt Christian Kersebaum wrote the paper.

Conflicts of Interest: The authors declare no conflict of interest. The founding sponsors had no role in the design of the study; in the collection, analyses, or interpretation of data; in the writing of the manuscript, and in the decision to publish the results.

\section{References}

1. Hoekstra, A.Y. Virtual Water Trade: Proceedings of the International Expert Meeting on Virtual Water Trade; Value of Water Research Report Series No 12; UNESCO-IHE: Delft, The Netherlands, 2003.

2. Hoekstra, A.Y.; Chapagain, A.K. Globalization of Water: Sharing the Planet's Freshwater Resources; Blackwell Publishing: Oxford, UK, 2008; p. 220.

3. Allan, J.A. Virtual water: A strategic resource. Global solutions to regional deficits. Ground Water 1998, 36, 545-546. [CrossRef]

4. Hoekstra, A.Y.; Hung, P.Q. Globalisation of water resources: International virtual water flows in relation to crop trade. Glob. Environ. Chang. 2005, 15, 45-56. [CrossRef] 
5. Berger, M.; Finkbeiner, M. Methodological Challenges in Volumetric and Impact-Oriented Water Footprints. J. Ind. Ecol. 2013, 17, 79-89. [CrossRef]

6. Hoekstra, A.Y.; Chapagain, A.K. Water footprints of nations: Water use by people as a function of their consumption pattern. Water Resour. Manag. 2007, 21, 35-48. [CrossRef]

7. Liu, J.; Zehnder, A.J.B.; Yang, H. Global consumptive water use for crop production: The importance of green water and virtual water. Water Resour. Res. 2009, 45, W05428. [CrossRef]

8. Mekonnen, M.M.; Hoekstra, A.Y. A global and high-resolution assessment of the green, blue and grey water footprint of wheat. Hydrol. Earth Syst. Sci. 2010, 14, 1259-1276. [CrossRef]

9. Siebert, S.; Döll, P. Quantifying blue and green virtual water contents in global crop production as well as potential production losses without irrigation. J. Hydrol. 2010, 384, 198-207. [CrossRef]

10. Hoekstra, A.Y.; Chapagain, A.K.; Aldaya, M.M.; Mekonnen, M.M. The Water Footprint Manual: Setting the Global Standard; Water Footprint Network Earthscan: London, UK, 2011; p. 203.

11. Jensen, M.E.; Burman, R.D.; Allen, R.G. Evapotranspiration and Irrigation Water Requirements. In ASCE Manuals and Reports on Engineering Practice; American Society of Civil Engineers: New York, NY, USA, 1990; Volume 70, p. 360.

12. Weiß, M.; Menzel, L. A global comparison of four potential evapotranspiration equations and their relevance to stream flow modelling in semi-arid environments. Adv. Geosci. 2008, 18, 15-23. [CrossRef]

13. Allen, R.G.; Pereira, L.S.; Raes, D.; Smith, M. Crop Evapotranspiration: Guidelines for Computing Crop Water Requirements; FAO Irrigation and Drainage Paper 56; Food and Agriculture Organization: Rome, Italy, 1998.

14. Smith, M.; Allen, R.; Pereira, L. Revised FAO Methodology for Crop Water Requirements. In Proceedings of the Consultants Meeting on Management of Nutrients and Water in Rainfed Arid and Semi-Arid Areas, Vienna, Austria, 26-29 May 1997; International Atomic Energy Agency: Vienna, Austria, 1998; pp. 51-58.

15. Mekonnen, M.M.; Hoekstra, A.Y. The green, blue and grey water footprint of crops and derived crop products. Hydrol. Earth Syst. Sci. 2011, 15, 1577-1600. [CrossRef]

16. Trnka, M.; Eitzinger, J.; Dubrovsky, M.; Semerádová, D.; Stepánek, P.; Hlavinka, P.; Balek, J.; Skala, K.P.; Farda, A.; Formayer, H.; et al. Is rainfed crop production in central Europe at risk? Using a regional climate model to produce high resolution agroclimatic information for decision makers. J. Agric. Sci. 2010, 148, 639-656. [CrossRef]

17. Trnka, M.; Olesen, J.E.; Kersebaum, K.C.; Skjelvag, A.O.; Eitzinger, J.; Seguin, B.; Peltonen-Sainio, P.; Rötter, R.; Iglesias, A.; Orlandini, S.; et al. Agroclimatic conditions in Europe under climate change. Glob. Chang. Biol. 2011, 17, 2298-2318. [CrossRef]

18. Wassenaar, T.; Lagacherie, P.; Legros, J.-P.; Rounsevell, M.D.A. Modelling wheat yield responses to soil and climate variability at the regional scale. Clim. Res. 1999, 11, 209-220. [CrossRef]

19. Kersebaum, K.C.; Lorenz, K.; Reuter, H.I.; Schwarz, J.; Wegehenkel, M.; Wendroth, O. Operational use of agro-meteorological data and GIS to derive site specific nitrogen fertilizer recommendations based on the simulation of soil and crop growth processes. Phys. Chem. Earth 2005, 30, 59-67. [CrossRef]

20. Kersebaum, K.C.; Nendel, C. Site-specific impacts of climate change on wheat production across regions of Germany using different $\mathrm{CO}_{2}$ response functions. Eur. J. Agron. 2014, 52, 22-32. [CrossRef]

21. Walker, W.E.; Harremoës, P.; Rotmans, J.; Van der Sluijs, J.P.; Van Asselt, M.B.A.; Janssen, P.; Von Krauss, M.P.K. Defining uncertainty: A conceptual basis for uncertainty management in model-based decision support. Integr. Assess. 2003, 4, 5-17. [CrossRef]

22. Scherer, L.; Pfister, S. Dealing with uncertainty in water scarcity footprints. Environ. Res. Lett. 2016, 11, 054008. [CrossRef]

23. Palosuo, T.; Kersebaum, K.C.; Angulo, C.; Hlavinka, P.; Moriondo, M.; Olesen, J.; Patil, R.; Ruget, F.; Rumbaur, C.; Takac, J.; et al. Simulation of winter wheat yield and its variability in different climates of Europe: A comparison of eight crop growth models. Eur. J. Agron. 2011, 35, 103-114. [CrossRef]

24. Rötter, R.P.; Palosuo, T.; Kersebaum, K.C.; Angulo, C.; Bindi, M.; Ewert, F.; Ferrise, R.; Hlavinka, P.; Moriondo, M.; Nendel, C.; et al. Simulation of spring barley yield in different climatic zones of Northern and Central Europe: A comparison of nine crop models. Field Crops Res. 2012, 133, 23-36. [CrossRef]

25. Asseng, S.; Ewert, F.; Rosenzweig, C.; Jones, J.W.; Hatfield, J.L.; Ruane, A.; Boote, K.J.; Thorburn, P.; Rötter, R.P.; Cammarano, D.; et al. Quantifying uncertainties in simulating wheat yields under climate change. Nat. Clim. Chang. 2013, 3, 827-832. [CrossRef] 
26. Bassu, S.; Brisson, N.; Durand, J.-L.; Boote, K.J.; Lizaso, J.; Jones, J.W.; Rosenzweig, C.; Ruane, A.C.; Adam, M.; Baron, C.; et al. How do various maize crop models vary in their responses to climate change factors? Glob. Chang. Biol. 2014, 20, 2301-2320. [CrossRef] [PubMed]

27. Martre, P.; Wallach, D.; Asseng, S.; Ewert, F.; Rosenzweig, C.; Jones, J.W.; Hatfield, J.L.; Ruane, A.C.; Boote, K.J.; Thorburn, P.; et al. Evaluating an ensemble of 27 crop simulation models in diverse environments: Are multi-models better than one? Glob. Chang. Biol. 2015, 21, 911-925. [CrossRef] [PubMed]

28. Cammarano, D.; Rötter, R.P.; Asseng, S.; Ewert, F.; Wallach, D.; Martre, P.; Hatfield, J.L.; Jones, J.W.; Rosenzweig, C.; Ruane, A.C.; et al. Water use of wheat: Simulated patterns and sensitivity to temperature and $\mathrm{CO}_{2}$. Field Crops Res. 2016, 198, 80-92. [CrossRef]

29. Metzger, M.J.; Bunce, R.G.H.; Jongman, R.H.G.; Mucher, C.A.; Watkins, J.W. A climatic stratification of the environment of Europe. Glob. Ecol. Biogeogr. 2005, 14, 549-563. [CrossRef]

30. Mirschel, W.; Wenkel, K.-O.; Wegehenkel, M.; Kersebaum, K.C.; Schindler, U.; Hecker, J.-M. Müncheberg field trial data set for agro-ecosystem model validation. In Modelling Water and Nutrient Dynamics in Soil Crop Systems; Kersebaum, K.C., Hecker, J.-M., Mirschel, W., Wegehenkel, M., Eds.; Springer: Dordrecht, The Netherlands, 2007; pp. 219-243.

31. Mirschel, W.; Barkusky, D.; Hufnagel, J.; Kersebaum, K.C.; Nendel, C.; Laacke, L.; Luzi, K.; Rosner, G. Coherent multi-variable field data set of an intensive cropping system for agro-ecosystem modelling from Müncheberg, Germany. Open Data J. Agric. Res. 2016. [CrossRef]

32. Weigel, H.J.; Manderscheid, R. Crop growth responses to free air $\mathrm{CO}_{2}$ enrichment and nitrogen fertilization: Rotating barley, ryegrass, sugar beet and wheat. Eur. J. Agron. 2012, 43, 97-107. [CrossRef]

33. Eitzinger, J.; Trnka, M.; Hösch, J.; Zalud, Z.; Dubrovsky, M. Comparison of CERES, WOFOST and SWAP models in simulating soil water content during growing season under different soil conditions. Ecol. Model. 2004, 171, 223-246. [CrossRef]

34. Ventrella, D.; Stellacci, A.M.; Castrignanò, A.; Charfeddine, M.; Castellini, M. Effects of crop residue management on winter durum wheat productivity in a long term experiment in Southern Italy. Eur. J. Agron. 2016, 77, 188-198. [CrossRef]

35. Steduto, P.; Hsiao, T.; Raes, D.; Fereres, E. AquaCrop-The FAO crop model to simulate yield response to water: I. Concepts and underlying principles. Agron. J. 2009, 101, 426-437. [CrossRef]

36. Keating, B.A.; Carberry, P.S.; Hammer, G.L.; Probert, M.E.; Robertson, M.J.; Holzworth, D.; Huth, N.I.; Hargreaves, J.N.G.; Meinke, H.; Hochman, Z.; et al. An overview of APSIM, a model designed for farming systems simulation. Eur. J. Agron. 2003, 18, 267-288. [CrossRef]

37. Hansen, S.; Abrahamsen, P.; Petersen, C.T.; Styczen, M. Daisy: Model use, calibration and validation. Trans. ASABE 2012, 55, 1315-1333. [CrossRef]

38. Jones, J.W.; Hoogenbohm, G.; Porter, C.H.; Boote, K.J.; Batchelor, W.D.; Hunt, L.A.; Wilkens, P.W.; Singh, U.; Gijsman, A.J.; Ritchie, J.T. The DSSAT cropping system model. Eur. J. Agron. 2003, 18, 235-265. [CrossRef]

39. Kroes, J.G.; van Dam, J.C.; Groenendijk, P.; Hendriks, R.F.A.; Jacobs, C.M.J. SWAP Version 3.2(26). Theory Description and User Manual; Alterra-Report; Alterra Research Institute: Wageningen, The Netherlands, 2009; Volume 1649, p. 284.

40. Stöckle, C.O.; Donatelli, M.; Nelson, R. CropSyst, a cropping systems simulation model. Eur. J. Agron. 2003, 18, 289-307. [CrossRef]

41. Kersebaum, K.C.; Hecker, J.M.; Mirschel, W.; Wegehenkel, M. Modelling water and nutrient dynamics in soil-crop systems: A comparison of simulation models applied on common data sets. In Modelling Water and Nutrient Dynamics in Soil-Crop Systems; Kersebaum, K.C., Hecker, J.-M., Mirschel, W., Wegehenkel, M., Eds.; Springer: Dordrecht, The Netherlands, 2007; pp. 1-17.

42. Grunwald, S. GIS Gestürtzte Modellierung des Landschaftswasser und Stoffhaushalts mit dem Modifizerten Modell AGNPSm. Ph.D. Thesis, University Giessen, Giessen, Germany, 1997.

43. Confalonieri, R.; Orlando, F.; Paleari, L.; Stella, T.; Gilardelli, C.; Movedi, E.; Pagani, V.; Cappelli, G.; Vertemara, A.; Alberti, L.; et al. Uncertainty in crop model predictions: What is the role of users? Environ. Model. Softw. 2016, 81, 165-173. [CrossRef]

44. Manderscheid, R.; Weigel, H.-J. Drought stress effects on wheat are mitigated by atmospheric $\mathrm{CO}_{2}$ enrichment. Agron. Sustain. Dev. 2007, 27, 79-87. [CrossRef]

45. Kersebaum, K.C. Effects of climate change and elevated $\mathrm{CO}_{2}$ on wheat water consumption, yield and water footprint in three contrasting regions of Germany. Ital. J. Agromet. 2015, Si, 117-122. 
46. Fader, M.; Rost, S.; Müller, C.; Bondeau, A.; Gerten, D. Virtual water content of temperate cereals and maize: Present and potential future patterns. J. Hydrol. 2010, 384, 218-231. [CrossRef]

47. Kollas, C.; Kersebaum, K.C.; Nendel, C.; Manevski, K.; Müller, C.; Palosuo, T.; Armas-Herrera, C.M.; Beaudoin, N.; Bindi, M.; Charfeddine, M.; et al. Crop rotation modelling-A European model intercomparison. Eur. J. Agron. 2015, 70, 98-111. [CrossRef]

48. Salo, T.; Palosuo, T.; Kersebaum, K.C.; Nendel, C.; Angulo, C.; Ewert, F.; Bindi, M.; Calanca, P.; Klein, T.; Moriondo, M.; et al. Comparing the performance of eleven crop simulation models in predicting yield response to nitrogen fertilisation. J. Agric. Sci. 2016, 154, 1218-1240. [CrossRef]

49. Gabrielle, B.; Mary, B.; Roche, R.; Smith, P.; Gosse, G. Simulation of carbon and nitrogen dynamics in arable soils: A comparison of approaches. Eur. J. Agron. 2002, 18, 102-120. [CrossRef]

50. Rodrigo, A.; Recous, S.; Neel, C.; Mary, B. Modelling temperature and moisture effects on C-N transformations in soils: Comparison of nine models. Ecol. Mod. 1997, 102, 325-339. [CrossRef]

51. Ruane, A.C.; Hudson, N.I.; Asseng, S.; Camarrano, D.; Ewert, F.; Martre, P.; Boote, K.J.; Thorburn, P.J.; Aggarwal, P.K.; Angulo, C.; et al. Multi-wheat-model ensemble responses to interannual climate variability. Environ. Model. Softw. 2016, 81, 86-101. [CrossRef]

52. Asseng, S.; Ewert, F.; Martre, P.; Rötter, R.P.; Lobell, D.B.; Cammarano, D.; Kimball, B.A.; Ottman, M.J.; Wall, G.W.; White, J.W.; et al. Rising temperatures reduce global wheat production. Nat. Clim. Chang. 2015, 5, 143-147. [CrossRef]

(C) 2016 by the authors; licensee MDPI, Basel, Switzerland. This article is an open access article distributed under the terms and conditions of the Creative Commons Attribution (CC-BY) license (http://creativecommons.org/licenses/by/4.0/). 